\title{
Interrelation between grid systems and star polygons of muqarnas ground projection plans
}

\author{
Asli Agirbas $^{1 *} \mathbb{D}$, Gulnur Yildiz² and Murat Sahin ${ }^{1}$
}

\begin{abstract}
Many muqarnas ground projection plans contain stars with unequal edge lengths in their compositions. In this study, the geometric reasons behind the unequality of star edge lengths in muqarnas ground projection plans have been searched. The main gates with complex-looking muqarnas belonging to the period of Suleiman the Magnificent (Kanuni Sultan Suleyman), designed by Architect Sinan in Istanbul, have been selected to examine. From the data obtained by 3D laser scanning and from the verification made, it has been confirmed that there are stars with unequal edge lengths in these muqarnas plans. From the geometrical examinations made according to the shape grammar theory, it was concluded that the muqarnas plans were created using spider-web grid and square grid layouts. It was also concluded that these grid types cause some of the star edge lengths to be unequal.
\end{abstract}

Keywords: 3D Laser scanning, Muqarnas, Muqarnas plans, Geometric patterns, Design analysis

\section{Introduction}

Muqarnas is known as ornamentation used in Islamic architecture. Muqarnas can be of different types and complexity. However, according to many researchers such as Ozdural [1] and Garafalo [2], muqarnas are created by lifting compositions produced in two dimensions to the third dimension. When we look at two-dimensional muqarnas ground projection plans, we see stars like in Islamic patterns. As seen in the Islamic geometric pattern analysis in the books of Bonner [3] and Broug [4], the majority of the stars in Islamic patterns have equal edge lengths. Also, in the studies of Bourgoin [5], Schneider [6], Critchlow [7], Hankin [8], Cromwell [9], Bodner [10], Agirbas [11] and Redondo-Buitrago and Huylebrouck [12] regarding the stars in Islamic patterns, this situation can be clearly seen. As it can be noticed in the muqarnas plan drawings of Uluengin [13], the stars in the muqarnas plans can be with or without equal edge lengths. We can call stars with equal edge lengths as regular stars and stars with unequal edge lengths as irregular

\footnotetext{
*Correspondence: asliagirbas@gmail.com

${ }^{1}$ Department of Architecture, Ozyegin University, Istanbul, Turkey

Full list of author information is available at the end of the article
}

stars. The muqarnas at main gates, which create a certain volume, generally have a wide variety of star polygon compositions in their ground projection plans. The edge lengths of the stars in these star compositions can also be equal or not.

The examples in Necipoglu's [14] and Uluengin's [13] books show stars with unequal edge lengths in muqarnas projection plans. Although the researchers such as Ozdural [15], Dold-Samplonius and Harmsen [16], Elkhateeb [17], Hamekasi et al. [18], Castera [19], Kharazmi and Sarhangi [20], Gherardini and Leali [21], Kashef [22], Yaghan [23] and Takahashi [24] examined the structure of the muqarnas from various aspects, none of them focussed on the geometric reason for the unequal edge lengths of the stars in the muqarnas plans. Agirbas and Yildiz's previous study [25] is the first study related to the geometrical reason for unequal edge lengths of the stars in the muqarnas plans. For this, muqarnas at the main gate of Atik Valide Mosque, which is simpler than many other muqarnas at main gates, were chosen to be examined, and this muqarnas was examined in its second and third dimensions in the framework of shape grammar theory. According to this study, the reason of the edge lengths of the stars in the muqarnas plan being unequal

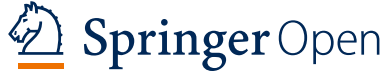

(c) The Author(s) 2022 Open Access This article is licensed under a Creative Commons Attribution 4.0 International License, which permits use, sharing, adaptation, distribution and reproduction in any medium or format, as long as you give appropriate credit to the original author(s) and the source, provide a link to the Creative Commons licence, and indicate if changes were made. The images or other third party material in this article are included in the article's Creative Commons licence, unless indicated otherwise in a credit line to the material. If material is not included in the article's Creative Commons licence and your intended use is not permitted by statutory regulation or exceeds the permitted use, you will need to obtain permission directly from the copyright holder. To view a copy of this licence, visit http://creativecommons.org/licenses/by/4.0/. The Creative Commons Public Domain Dedication waiver (http://creativeco mmons.org/publicdomain/zero/1.0/) applies to the data made available in this article, unless otherwise stated in a credit line to the data. 
is that the plan layout may have been created with an ellipse. The ellipse layout fits perfectly with the plan obtained as a result of 3D laser scanning [25].

As the next step of the mentioned study, it was aimed to analyze the stars in the plans of the more complexlooking muqarnas at main gates, and to investigate the geometrical reasons of unequal edge lengths of the stars. In this study, the same method based on shape grammar was used. The geometric formation of the muqarnas plan was created based on the rules.

Main gates are monumental gates of public buildings [26]. In various periods of history, they gained importance as the most striking and prominent element of the outer mass [27]. In Islamic architecture, it is seen that the main gates are usually accompanied by muqarnas, and these muqarnas are more magnificent than the muqarnas in other parts of the building. However, the muqarnas on some main gates are more volumetric, layered and deeper than others, and therefore they are more complex mathematically. This makes the main gates with this type of muqarnas more imposing and ostentatious. Therefore, this study focuses on this type of main gate muqarnas. In addition, in this study, it has been focussed on the works of Architect Sinan in Istanbul, and particularly focussed on the main gate entrance of the mosques. In this way, the scope of the study has been limited according to the time and region. The muqarnas to be analyzed were preexamined on the basis of the difference in their plans. In this preliminary study, by looking at the most-armed star in the muqarnas frame, muqarnas with various numbers of the most-armed stars (muqarnas at Suleymaniye Mosque has 8-armed star as the most-armed completed star, muqarnas at Sehzade Mosque has 10-armed star as the most-armed completed star, muqarnas at Mihrimah Sultan Mosque has 7-armed star as the most-armed completed star, muqarnas at Atik Valide Mosque has 6-armed star as the most-armed completed star) were selected for examination. In this way, it is aimed to examine the muqarnas plans that are as different from each other as possible on the basis of plan.
The muqarnas at the main gates of Mihrimah Mosque, Sehzade Mosque and Suleymaniye Mosque, which were designed by Architect Sinan in the period of Suleiman the Magnificent, were selected to examine in this study. The characteristics of these mosques and the characteristics of the Atik Valide Mosque, which was the subject of the previous study, are given in Table 1 . However, the geometries of the muqarnas plans obtained by $3 \mathrm{D}$ laser scanning were as complex as their lookings. As a first impression, it was seen that two of the three muqarnas plans had a radial layout as in the Atik Valide Mosque main gate muqarnas plan and one had a gridal layout.

Although we tried to apply an elliptical layout for these radial plans as we tried in the muqarnas plan of the Atik Valide Mosque main gate, we could not achieve a satisfactory result. We thought that a simpler way should be followed to create these more complex muqarnas plans. These muqarnas with radial plans had a different aspect than that of main gate muqarnas of the Atik Valide Mosque. The arms of the stars were looking at each other (reciprocally touching arms) as if they were lined up on a strip. There were many rows of stripes in this way. When we look at the muqarnas plan composition, this was the most dominant point. Therefore, we focused on these dominant strips in these muqarnas plans.

\section{Methodology}

In order to find the true proportions of muqarnas plans, the main gates of the mosques were first scanned with 3D laser scanning. FARO 3D laser scanning tool was used for this process. The scans were performed several times for each main gate to create precise models. All scans were transferred to the Scene program and the scans were overlapped for each gate (Fig. 1). After this stage, the point cloud models of main gate muqarnas were formed (Fig. 2). Since the research will be carried out on the projection plans of the muqarnas, orthophoto of the muqarnas models, which were obtained as point cloud, were created. These images were used as a base in the muqarnas plan drawings (Fig. 3).

Table 1 General information about the mosques where the main gate muqarnas are analyzed. The date ranges are taken from Gunay [28], other information is from Eris et al. [29] and Seker [30]

\begin{tabular}{|c|c|c|c|c|}
\hline Name of the mosque & Location & Architect & Construction date & Explanations \\
\hline Mihrimah Sultan Mosque & Uskudar, Istanbul & Architect Sinan & $1540-1548$ & $\begin{array}{l}\text { It is the mosque built by Suleiman the Magnificent on behalf of } \\
\text { his daughter Mihrimah Sultan }\end{array}$ \\
\hline Sehzade Mosque & Fatih, Istanbul & Architect Sinan & $1543-1548$ & $\begin{array}{l}\text { It is the mosque built by Suleiman the Magnificent on behalf of } \\
\text { his son Sehzade Mehmet }\end{array}$ \\
\hline Suleymaniye Mosque & Fatih, Istanbul & Architect Sinan & $1550-1557$ & $\begin{array}{l}\text { It is the mosque built by Suleiman the Magnificent on behalf } \\
\text { of himself }\end{array}$ \\
\hline Atik Valide Mosque & Uskudar, Istanbul & Architect Sinan & $1570-1579 / 1583$ & It was built by Murad the III's mother Nurbanu Sultan \\
\hline
\end{tabular}




\begin{tabular}{llll}
\hline \multicolumn{1}{|c|}{ Photograph } & $\begin{array}{c}\text { The locations where the device is } \\
\text { positioned while laser scanning } \\
\text { (indicated by blue dots) }\end{array}$ & Point cloud model \\
$\begin{array}{l}\text { Mihrimah } \\
\text { Mosque }\end{array}$ &
\end{tabular}

Sehzade Mosque
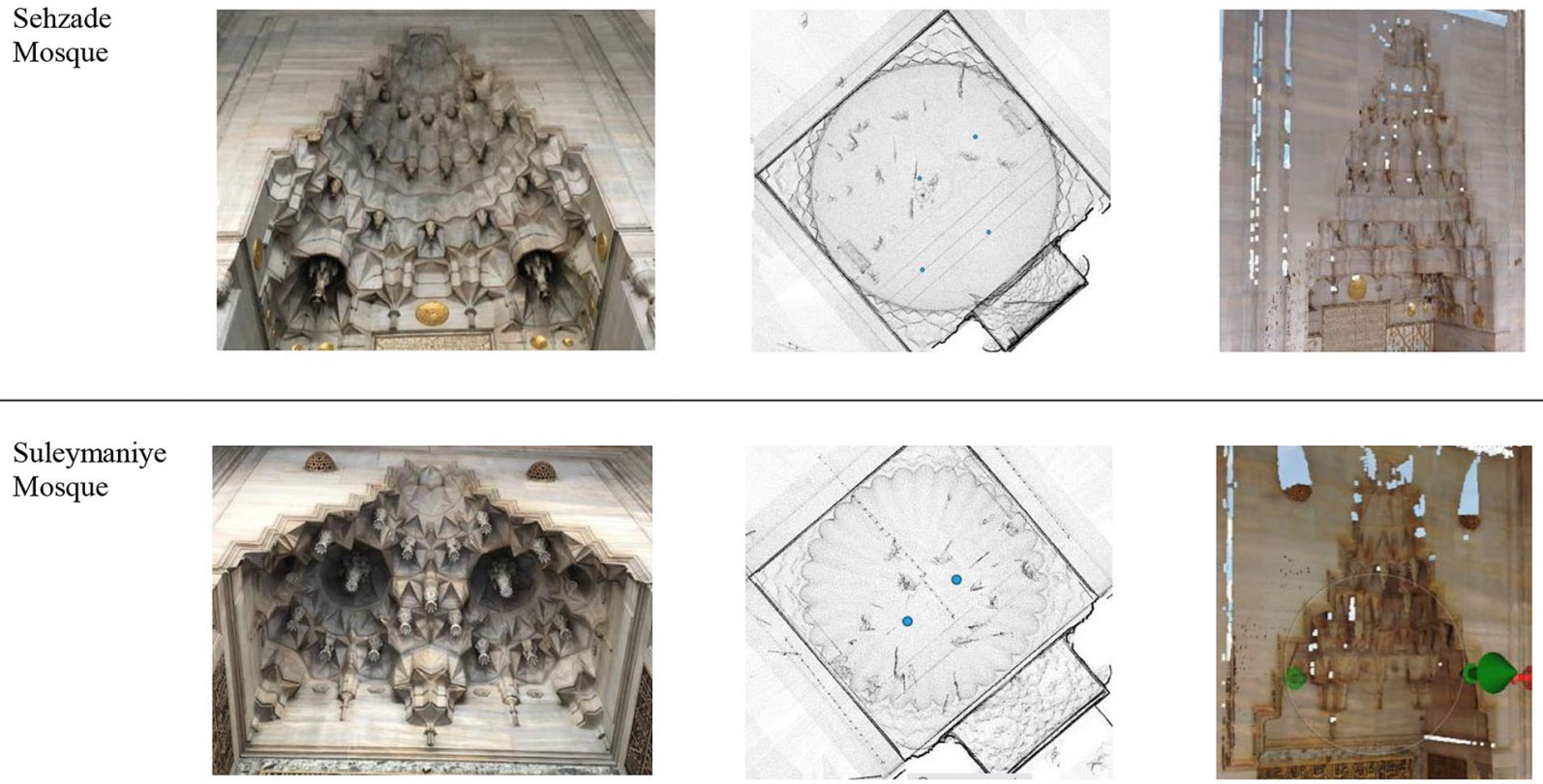

Fig. 1 Analyzed main gate muqarnas

The projection plans of muqarnas were prepared by using the orthophotos. While doing this, AutoCAD program was used. The muqarnas plans were examined through the shape grammar theory. According to the shape grammar theory, the forms are examined based on rules [31,32]. The number of the rules depends on the type of the shapes, and the shapes are modified according to the rule series. The number of the rules can be changed according to the complexity of the analysed geometry. Therefore, the basic shapes and the reshaping of these shapes based on mathematical rules were taken as a methodology for the creation of the forms in the muqarnas plans.
In the book of Necipoglu [14], edited construction lines (layouts) for various muqarnas plans in Topkapi scroll segments have been drawn. It has been revealed that many of plan layouts in the scroll consist of radial networks and many circles. Also, it can be seen that, Uluengin [13] (architect born in 1920) used partial radial networks and circles for creation of some radial muqarnas plan hand drawings in his building survey studies. We also use radial networks and circles to form radial muqarnas plan layouts.

In this study, spider web segmentation dimensions are also determined for radial muqarnas plans according to the sizes of the units such as stars, star arms and 


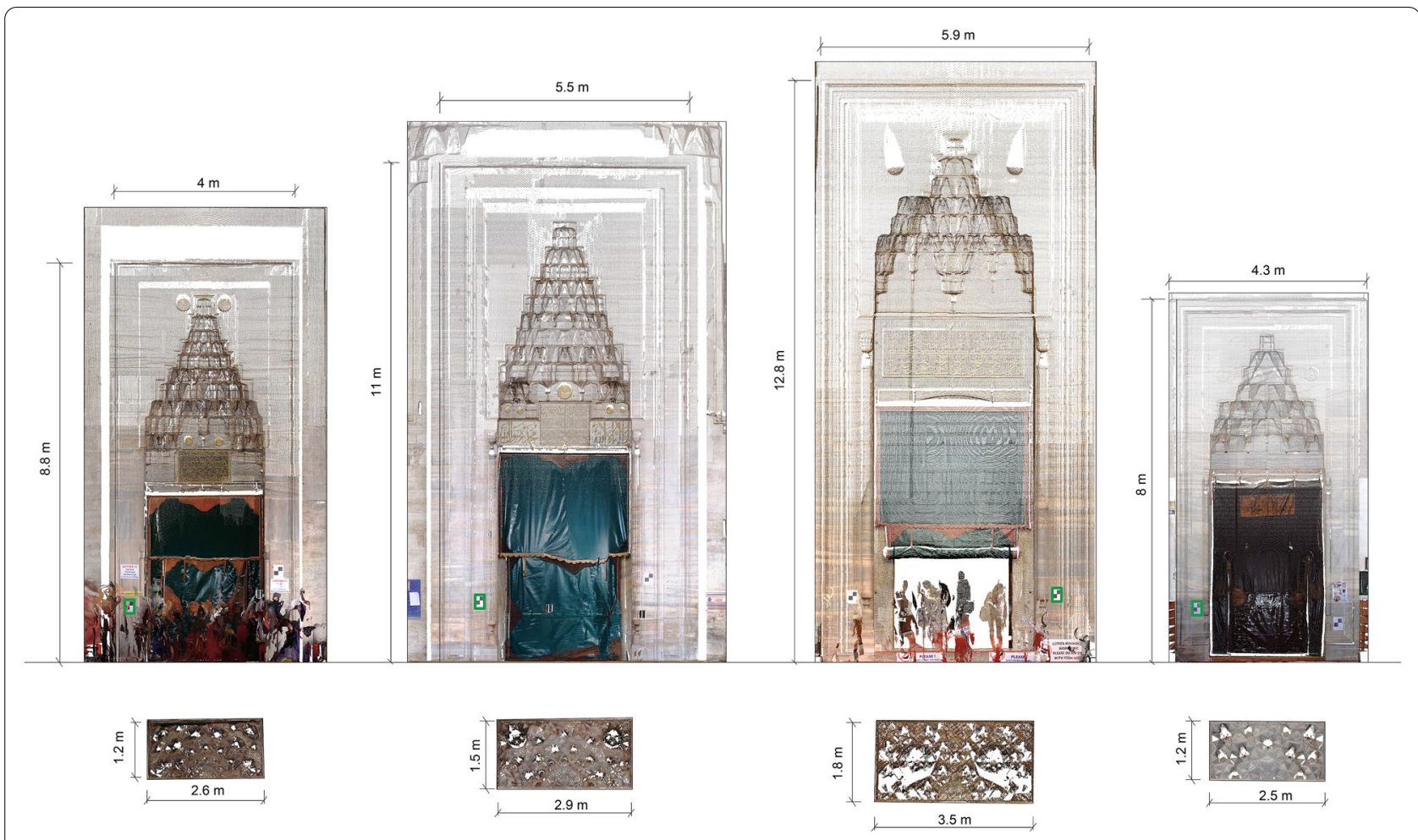

Fig. 2 Proportional front views of the main gates, obtained from the point cloud model (The main gate of Mihrimah Sultan Mosque, The main gate of Sehzade Mosque, The main gate of Suleymaniye Mosque, The main gate of Atik Valide Mosque, respectively)

star centers. And, the precise sizes of the units have been obtained with the laser scanning. The horizontal and vertical sizes of the grid have been determined according to the completed star units. The actual muqarnas plan (cropped plan) may not include complete star units at corners. For the analysis, the star units have been kept as complete stars, since the plans have been examined according to the shape grammar theory. Also, this method helps to see the family of the half stars at the corners in the whole picture and helps to determine the equality of the star arms mathematically. Furthermore, according to Uluengin's [13] findings, Ottoman craftsmen did not produce a separate layout for each work, but used different parts of a layout for different places (e.g. main gate, mihrab, column heading) (Fig. 4). That's why, it has been found appropriate to draw the complete picture of the muqarnas with completed stars (complete layout). After drawing the complete picture of the muqarnas, it has been cropped according to the actual frame. The intermediary parts that are not parts of the star compositions have been added to the rule set after cropping.

No historical documents have been found regarding to the drawing principles of the analysed muqarnas cases. However, there are hand drawing of Sedat Cetintas [33] (architect born in 1889), which include the muqarnas at main gates of Suleymaniye Mosque and Sehzade Mosque $[34,35]$. When the results of laser scanning and Cetintas's building survey drawings are compared, it is seen that they overlap with each other.

\section{Results and discussion}

\section{The plan formation of muqarnas at Mihrimah Sultan Mosque main gate}

The plan formation of muqarnas at Mihrimah Sultan Mosque main gate was examined within the framework of the shape grammar theory. The rule-based examination of the forms is given in Figs. 5, 6, 7, 8, 9 and Additional file 1: Movie S1. The detailed explanation of the rules is listed below.

- For the geometric analysis of the selected muqarnas plan, main axes with $30^{\circ}$ angle between them, and intermediary axes with $15^{\circ}$ angle to the main axes were created (rule 1 , sub rule 1 ). With reference to these axes, a radial grid system was created at equal intervals similar to the spider-web grid (rule 1, sub rule 2). In this study, this system will be called as spider-web grid.

- To create the first star, a circle was created in the center of the spider-web grid. The intersection points 


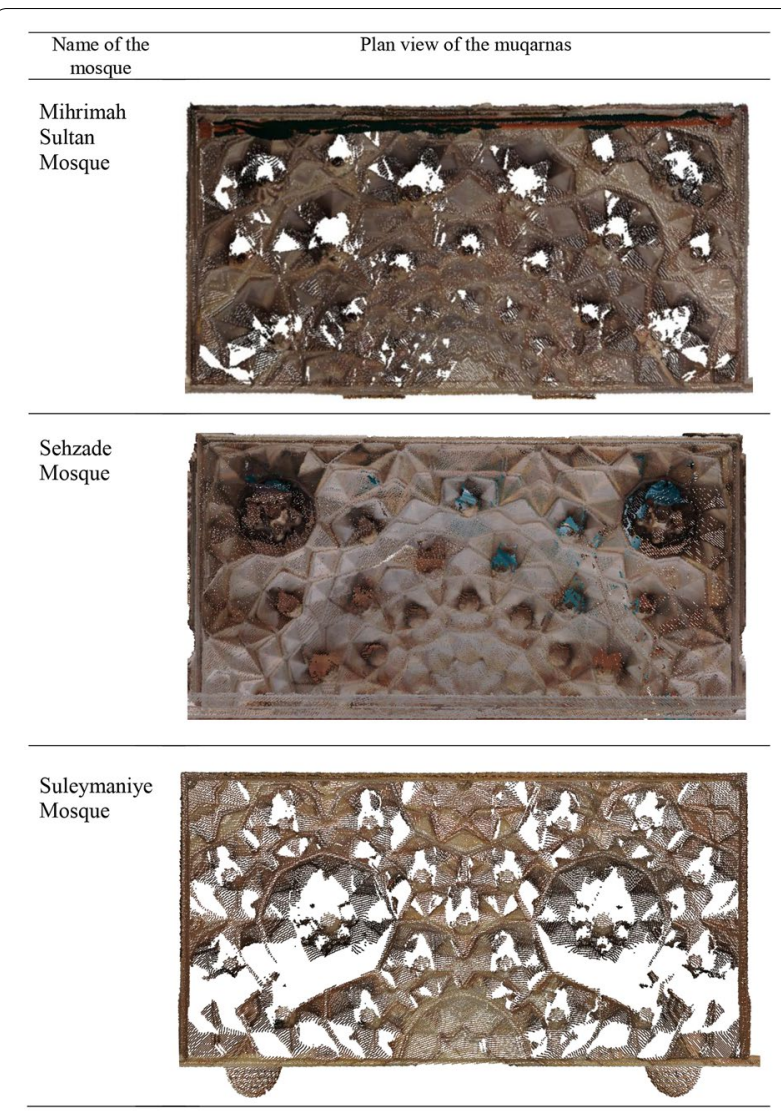

Fig. 3 Orthophotos of the muqarnas obtained from the point cloud model

of this circle with the intermediary axes and the intersection points of the main axes with the first strip of the spider-web grid were determined (rule 2, sub rule 1). Afterwards, the first star was created via forming lines between these points (rule 2, sub rule 2).

- For the second star formation, another circle was created. The intersection points between this circle and the intermediary axes were determined (rule 3, sub rule 1). By creating lines between these points and the points determined during the first star formation, a second star was created (rule 3, sub rule 2).

- For the third star formation, the intersection points between the second strip of the spider-web grid and the main axes were determined (rule 4, sub rule 1). By forming lines between these points and the points determined in the formation of the second star, the third star was created (rule 4, sub rule 2).

- For the formation of five-point irregular star polygon in rule 5, a reference circle was created using the points determined on the grid (rule 5 , sub rule 1). Then, a pentagon, which lies in the halfway of the space between the strips of the spider-web grid, was created (rule 5, sub rule 2). Irregular star was formed with using the circle and the pentagon (rule 5 , sub rule 3 ). The resulting five-point irregular star was replicated into 12 arranged in circular formation with reference to the origin point (rule 5, sub-rule 4). Thus, five-point irregular star formation was completed.

- For the formation of four-point irregular star polygon in rule 6 , the corresponding points were determined on the spider-web grid (rule 6, sub rule 1). Next, an octagon was created on the intersection of the fourth strip of the spider-web grid and the main axle (rule 6 , sub rule 2). The lines were formed between the octagon and the points, so the star arms were obtained (rule 6, sub rule 3). The resulting four-point irregular star was replicated into 12 arranged in circular formation with reference to the origin point (rule 6, sub rule 4). Thus, four-point irregular star formation was completed.

- For the formation of seven-point irregular star polygon in rule 7 , a circle was determined by referring to the points determined on the spider-web grid (rule 7, sub rule 1). Then, a heptagon was formed with four corners on the strips of spider-web grid (rule 7, sub rule 2). In order to create the star arms close to the center of the spider-web grid, the points determined on the circle and the lines were created between these points and the heptagon. The other arms of the star were obtained by creating isosceles triangles formed between the heptagon and the circle. In this muqarnas plan, as the Sehzade Mosque muqarnas plan formation, a slight length extension was made in the two star arms so that the arms of the stars could touch each other when replication was done (rule 7, sub rule 3). The resulting seven-point irregular star was replicated into 12 arranged in circular formation with reference to the origin point (rule 7 , sub rule 4). Thus, seven-point irregular star formation was completed. It is noteworthy that the arms of the stars are lined up on a spider strip at this stage.

- In rule 8, a five-point regular star polygon (a star with equal edge lengths) was created. First, a circle was obtained by referring to the seven-point irregular stars (rule 8, sub rule 1). Next, a pentagon was formed between the stripes of the spider-web grid. Meanwhile, the framework of the muqarnas plan was established (rule 8, sub rule 2). In order to create the star arms close to the center of the spider-web grid, the points were determined on the circle and the lines were created between these points and the pentagon. The remaining arms were copied around the pentagon as the same measure (rule 8 , sub rule 


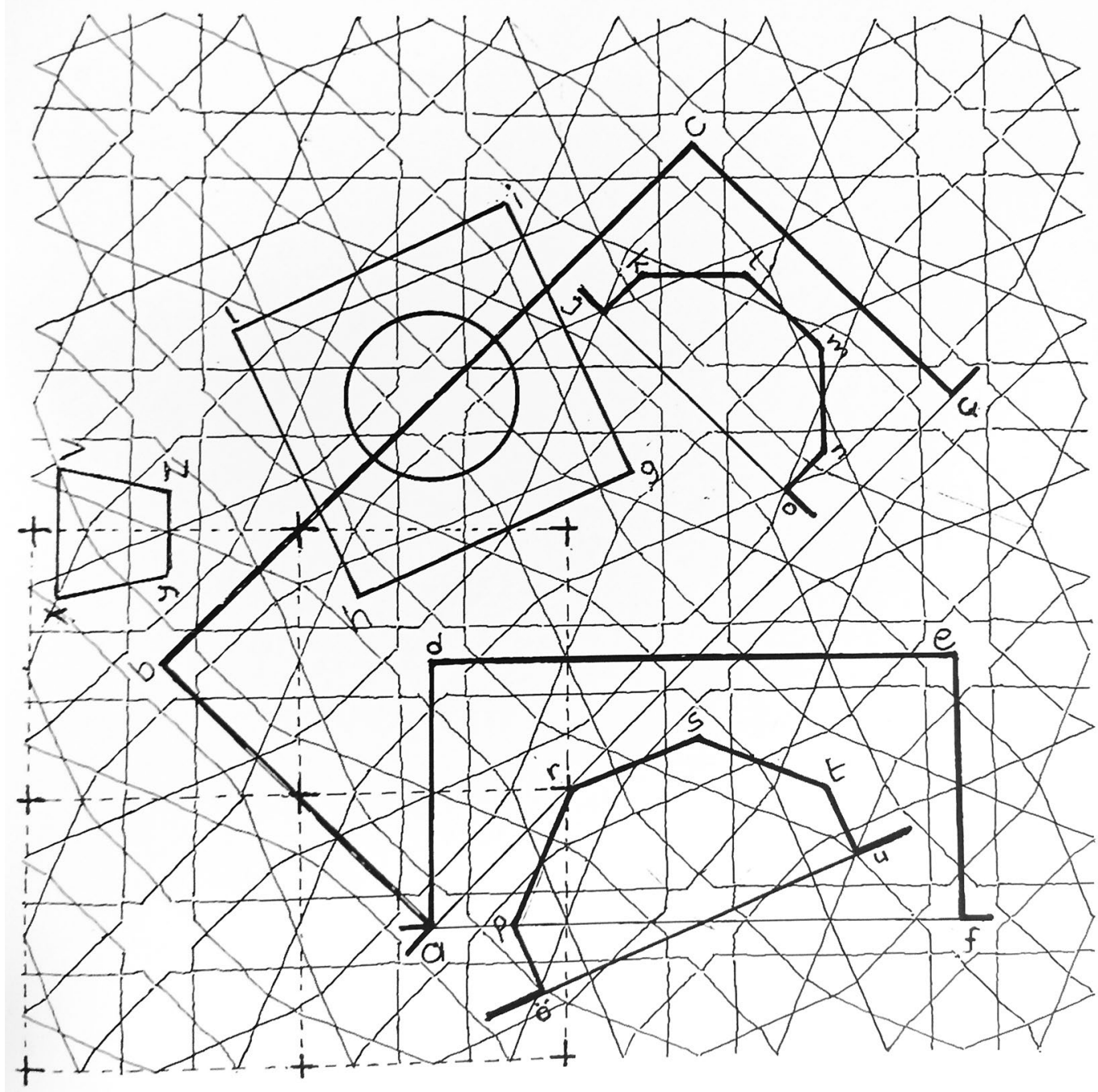

Fig. 4 Muqarnas plans produced from the same layout. Istanbul Suleymaniye Mosque main gate and Konya Selimiye Mosque main gate (a, b, $c$, ç points), Istanbul Beyazit Mosque courtyard west door and Edirne Selimiye Mosque main gate (a, d, e, f points), column header ( $g$, h, l, i points), mihrab (j, $k, l, m, n$, o points and $\ddot{0}, p, r, s, t, u$ points), lower part of minaret balcony ( $x, v, y, z$ points) [13]

3). The resulting five-point regular star was replicated in circular formation with reference to the origin point (rule 8 , sub rule 4). Thus, the formation of a five-point regular star with equal edge lengths was completed.

- In rule 9, a six-point irregular star polygon was created. First, a circle was obtained by referring to the points on five-point regular stars (rule 9, sub rule 1). Then an inner circle was placed in the center of the circle. A hexagon was also placed inside of the inner circle (rule 9, sub rule 2). Star arms were formed between determined points and the hexagon. Thus, six-point irregular star polygon was obtained (rule 9, sub rule 3). The resulting six-point irregular star was replicated into 12 arranged in circular formation with reference to the origin point (rule 9, sub rule 4).

- In rule 10 , the star, which we thought it could be an eight-point irregular star polygon as a whole, was created. First, a circle, which was based on the relevant star points, was formed at the corner of the frame (rule 10, sub rule 1). Then, an octagon was placed between the strips of spider-web grid (rule 10, sub rule 2). Star arms were formed between the sixpoint irregular stars and the octagon. Therefore, two arms of a star were obtained. These arms were replicated into four arranged in circular formation with reference to the circle center (rule 10, sub rule 3). The obtained eight-point irregular star was replicated 


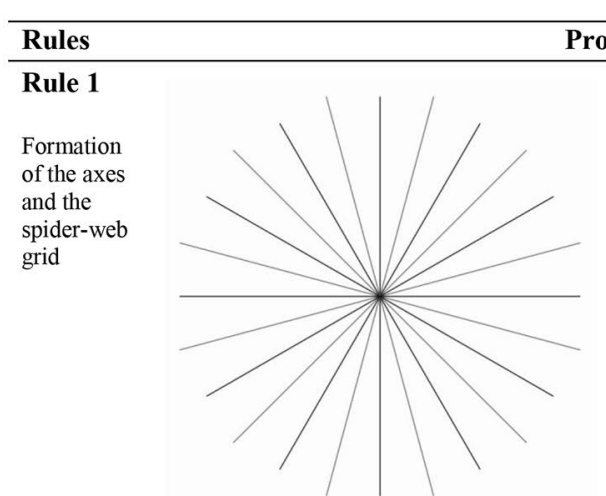

Sub rule 1

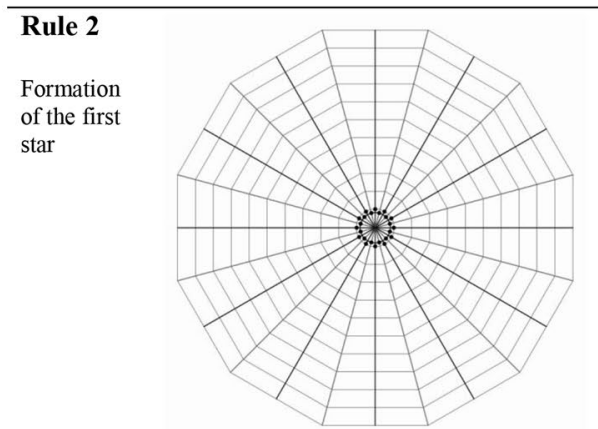

Sub rule 1

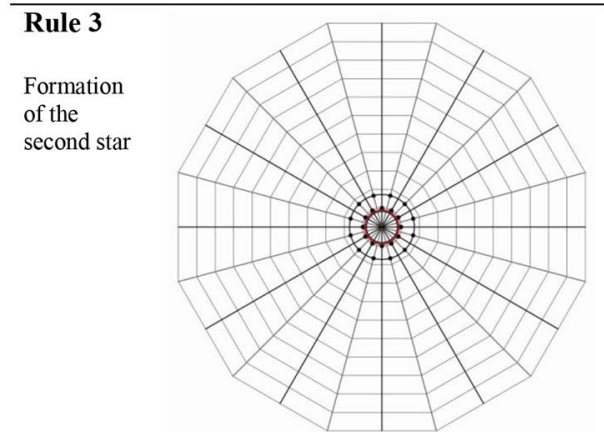

Sub rule 1

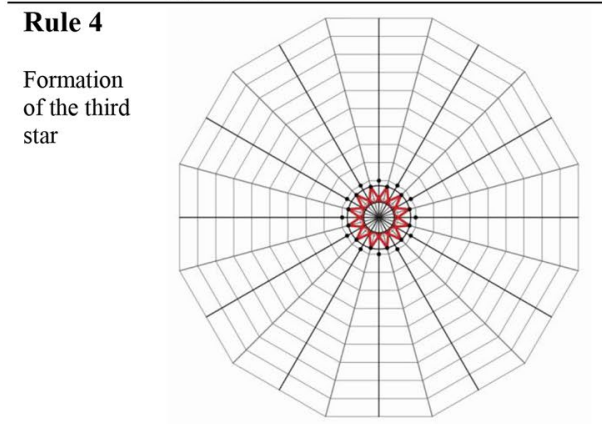

Sub rule 1

\section{rocess}

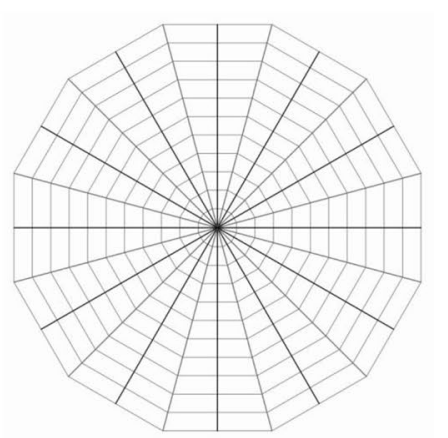

Sub rule 2

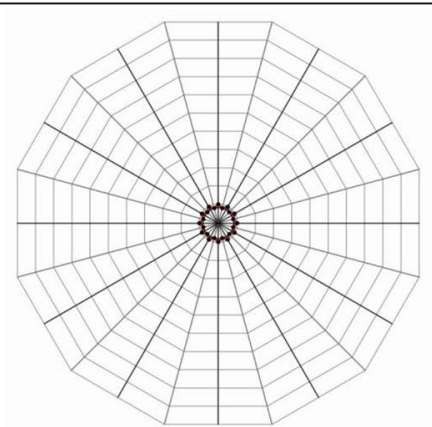

Sub rule 2

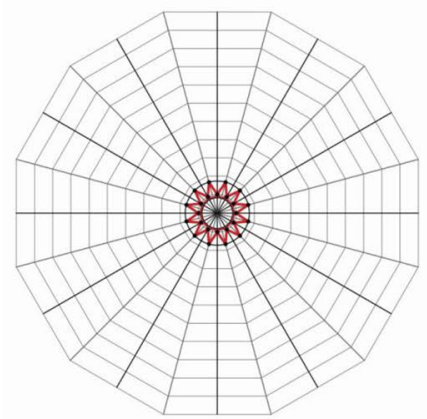

Sub rule 2

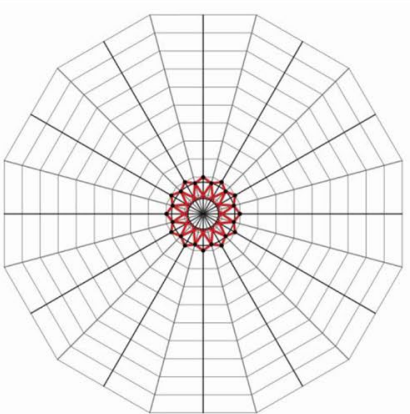

Sub rule 2

Fig. 5 Analysis of the muqarnas plan of Mihrimah Sultan Mosque main gate (rule 1 to rule 4) 


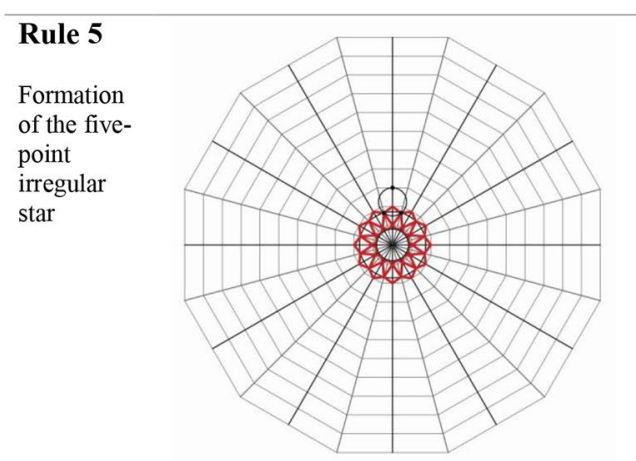

Sub rule 1
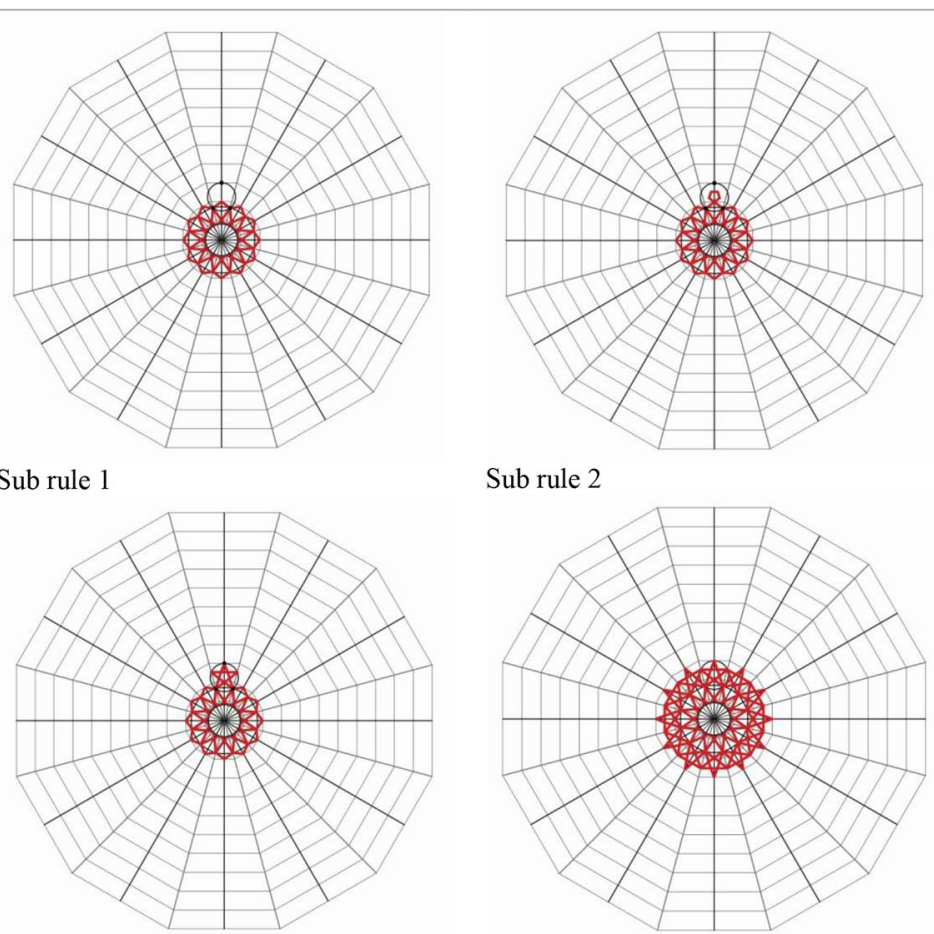

Sub rule 2

Sub rule 3

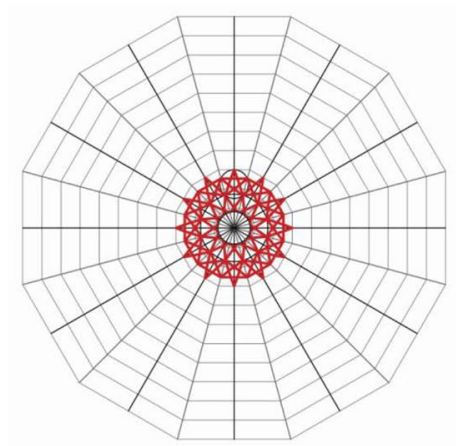

Sub rule 4
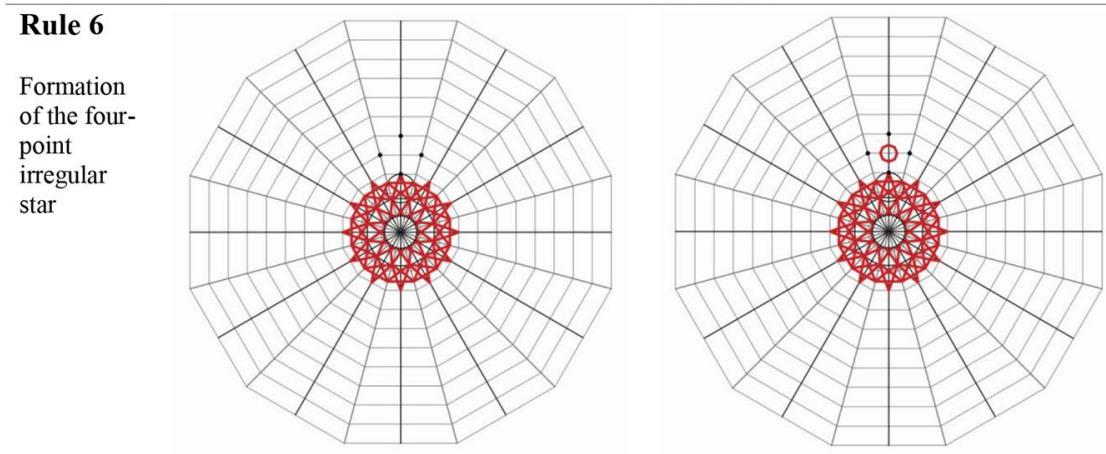

Sub rule 1

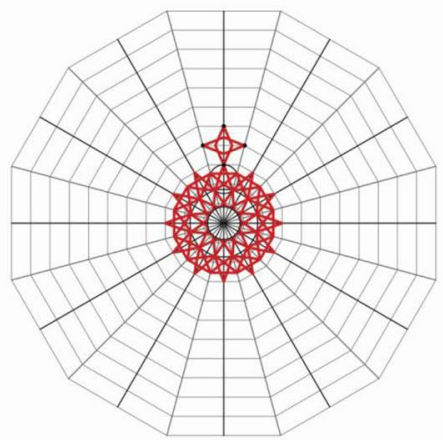

Sub rule 2

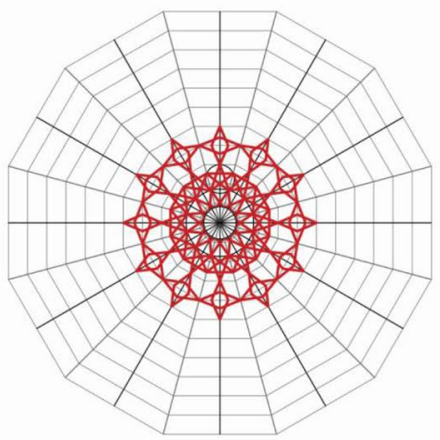

Sub rule 4

Fig. 6 Analysis of the muqarnas plan of Mihrimah Sultan Mosque main gate (rule 5 and rule 6) 


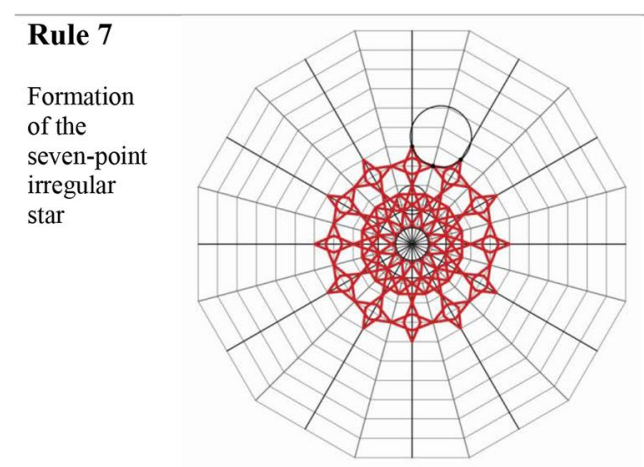

Sub rule 1

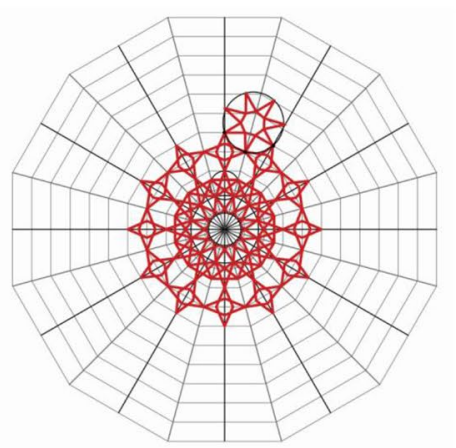

Sub rule 3
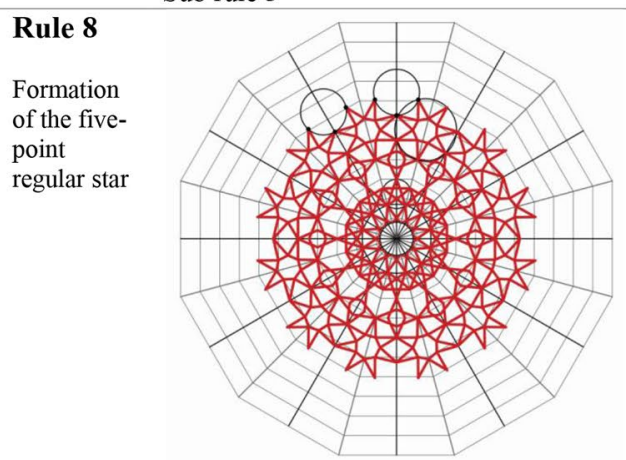

Sub rule 1

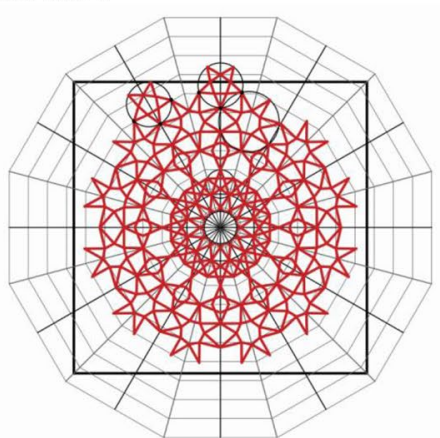

Sub rule 3

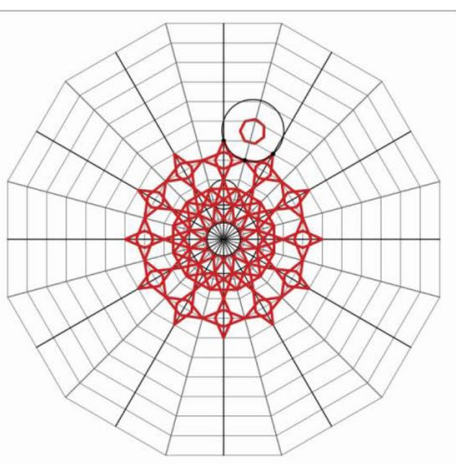

Sub rule 2

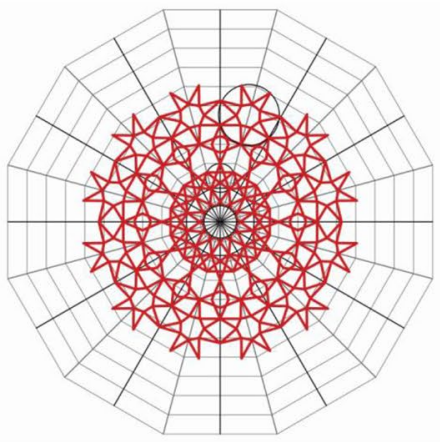

Sub rule 4

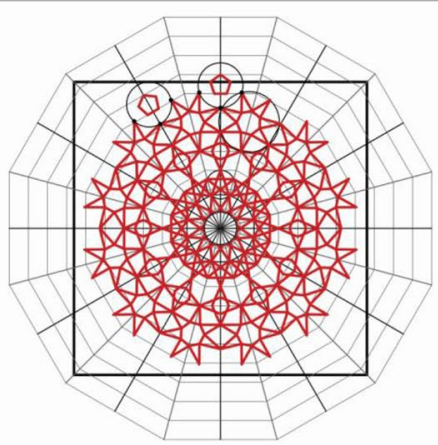

Sub rule 2

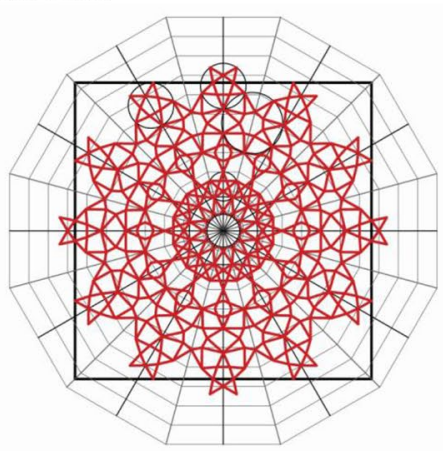

Sub rule 4

Fig. 7 Analysis of the muqarnas plan of Mihrimah Sultan Mosque main gate (rule 7 and rule 8) 


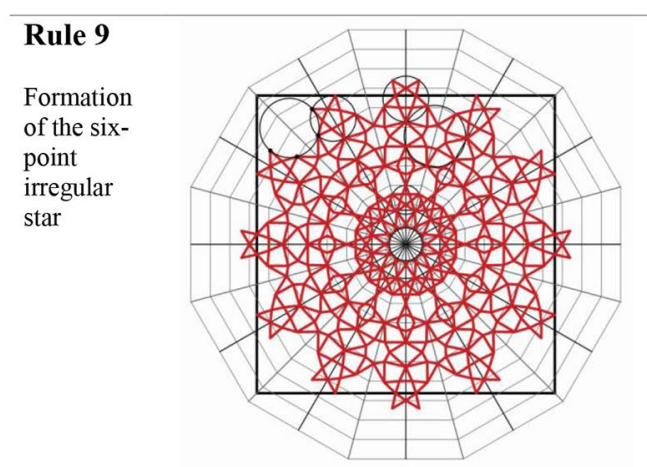

Sub rule 1

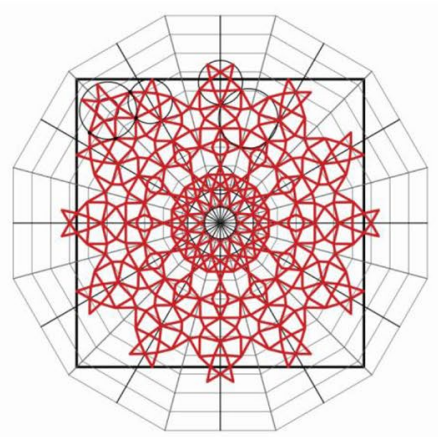

Sub rule 3

Rule 10

Formation of the eight-point irregular star

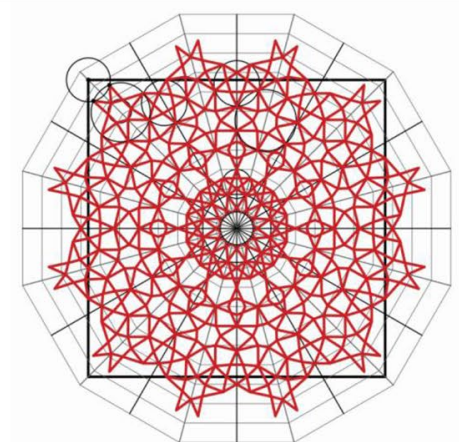

Sub rule 1

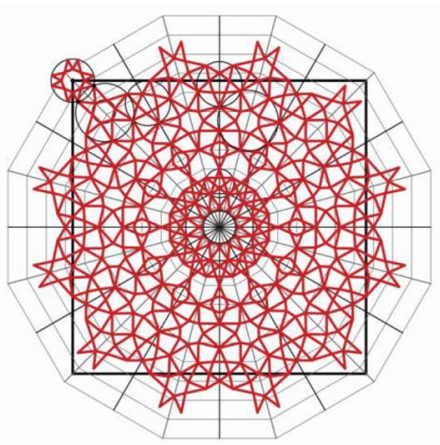

Sub rule 3

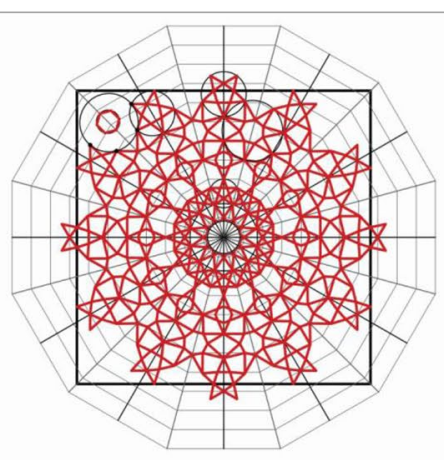

Sub rule 2

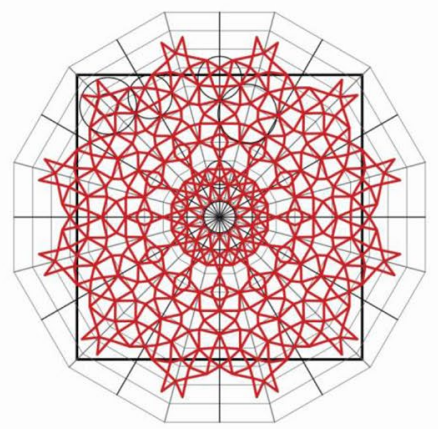

Sub rule 4

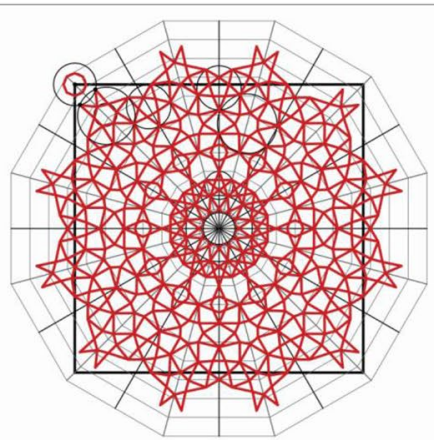

Sub rule 2

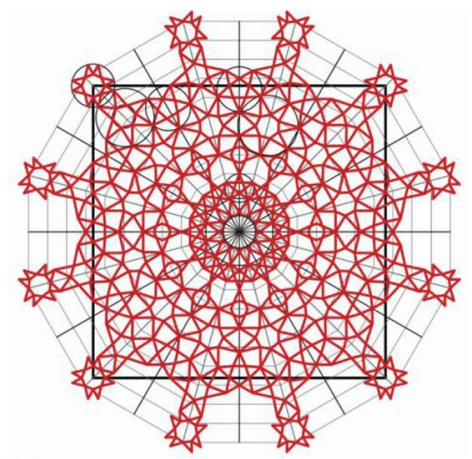

Sub rule 4

Fig. 8 Analysis of the muqarnas plan of Mihrimah Sultan Mosque main gate (rule 9 and rule 10) 


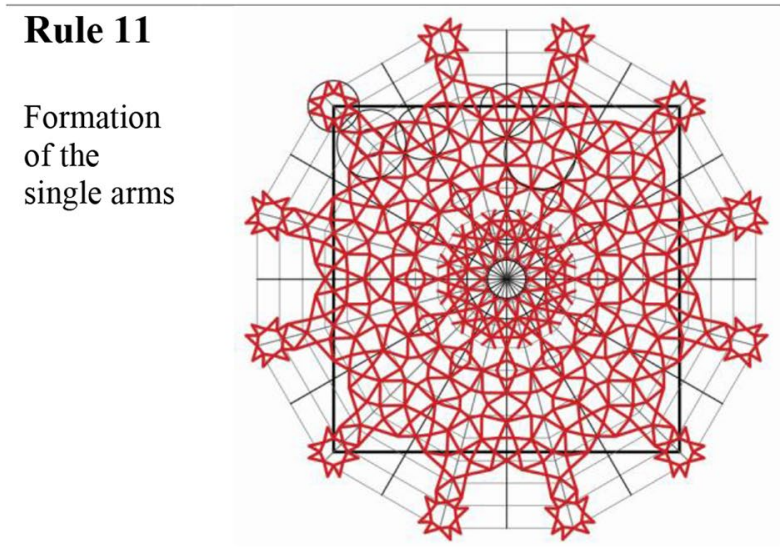

Sub rule 1

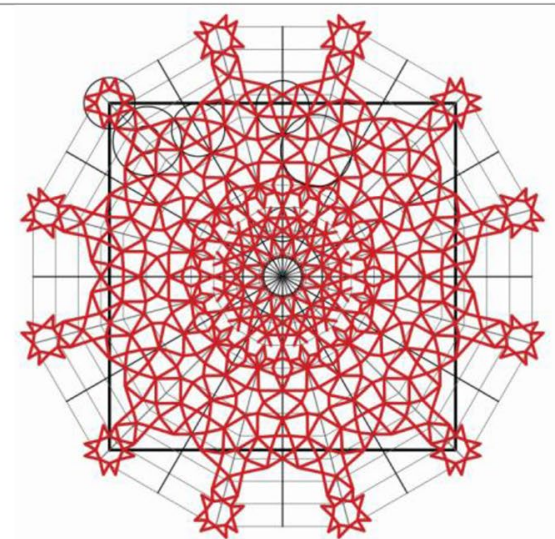

Sub rule 2

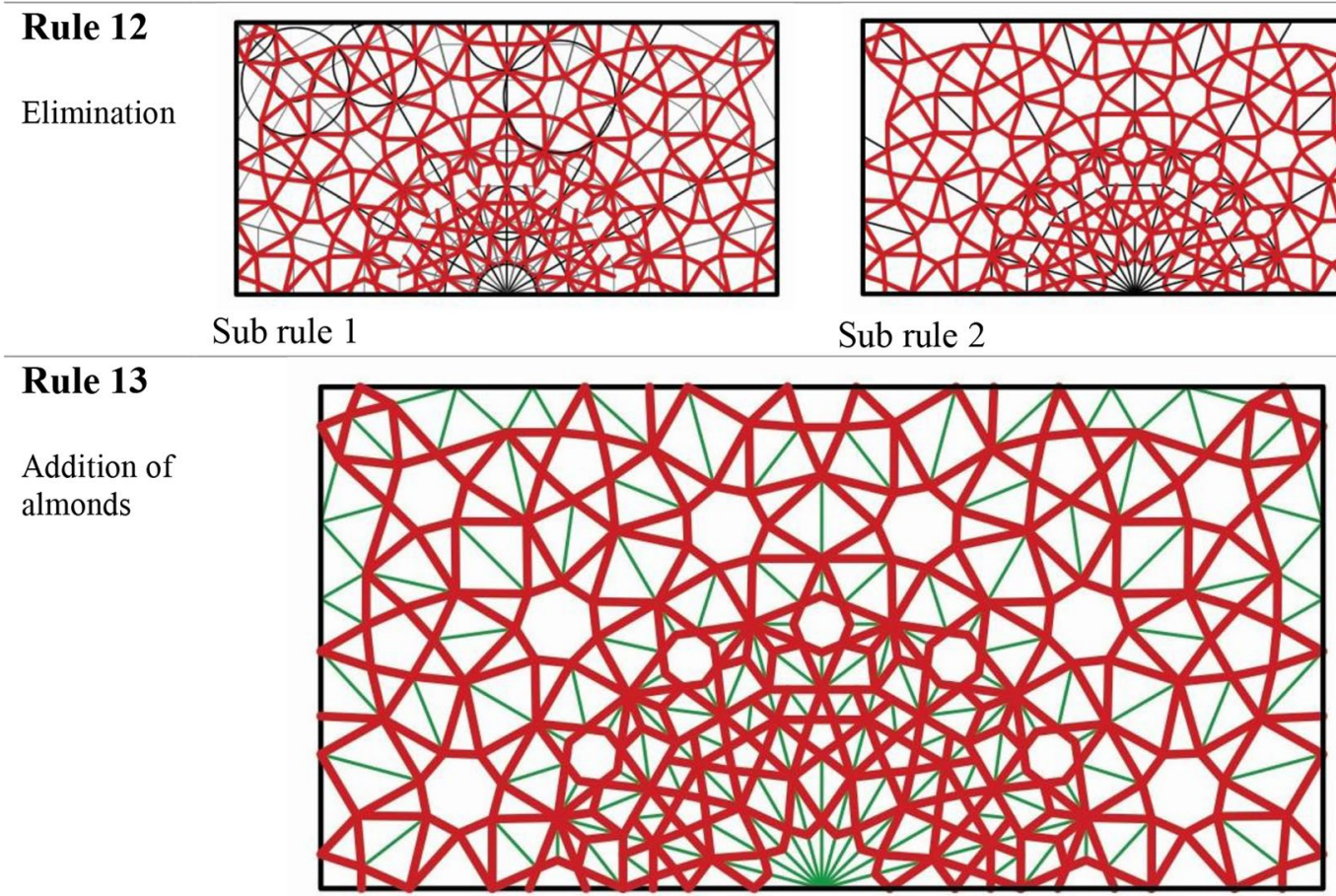

Fig. 9 Analysis of the muqarnas plan of Mihrimah Sultan Mosque main gate (rule 11 to rule 13)

into 12 arranged in circular formation with reference to the origin point (rule 10, sub rule 4). Thus, eightpoint irregular star was formed. This eight-point star is called irregular as it differs from the classical star polygon format. However, it has its own symmetry and consistency.

- In rule 11 , single arms (arms without a star) were added between the stars in the muqarnas plan. First row of the arms was created in the third strip of the spider-web grid (rule 11, sub rule 1). The second row of the arms was formed between the third and fourth stripes of the spider-web grid (rule 11, sub rule 2). These arms are like the fillings made on the parts between the created stars.

- In rule 12 , half of the pattern was eliminated, and the geometry of the muqarnas plan was obtained (rule 12, sub rule 1). Unnecessary grids and axes were deleted (rule 12, sub rule 2).

- Finally, in rule 13, the whole muqarnas composition was obtained by adding lines between the stars. These parts that were filled with the green lines represent almonds which are the certain type of 3D element of muqarnas (rule 13). 
Verification of the muqarnas plan form at Mihrimah Sultan Mosque main gate Verification of the five-point irregular star polygon It was found appropriate to convert the five-point irregular star created in rule 5 to five-point regular star for verification. The five-point irregular star has been converted to five-point regular star by bringing all arms to the same length. As a result, there were overlaps in the arms of the five-point regular star in the muqarnas plan composition. In addition, the arms of the five-point regular star and the arms of the four-point irregular star that are their upper neighbors, overlapped (Fig. 10a).

It is possible to prevent overlap by changing the arm lengths of the four-point irregular star, which is the neighbor of the five-point regular star. However, in this case, the four-point irregular star, which has its two arms are in equal length and the other two arms are also in equal length, becomes even more irregular. Consequently, three different arm lengths are formed in the four-point irregular star. However, even if the changes are made in the four-point star, the overlaps on the arms of the five-point regular star are not resolved (Fig. 10b).

\section{Verification of the four-point irregular star polygon}

It was found appropriate to convert the four-point irregular star created in rule 6 to four-point regular star for verification. All arm lengths of this four-point irregular star, which has its two arms are in equal length and the other two arms are also in equal length, were made equal. In this case, four-point star arms cannot touch each other in the muqarnas plan composition, and gaps remain between them. Also, the three-point stars, which should be formed between the four-point stars, cannot be formed due to the gaps (Fig. 10c).

\section{Verification of the seven-point irregular star polygon}

It was found appropriate to convert the seven-point irregular star formed in rule 7 to seven-point regular star for verification. All the arm lengths of the seven-point star were made equal in length and at the same time, all arms were converted into isosceles triangles. In this case, the arms of the seven-point stars cannot touch each other and the gaps remain between the arms. In addition, some of the seven-point star arms do not touch with neighboring stars, and the gaps remain between the arms (Fig. 10d).

An experiment was made via scaling up the regularized seven-point stars with their lower arms touching each other. In this case, even if the lower arms of the sevenpoint stars touch each other, the upper arms do not touch each other. Again, there are gaps between the arms. However, in this case, it is necessary to make changes to the arms of their neighbors, which are in the lower part of the seven-point stars. The upper part arms of the fourpoint irregular stars should be shortened. In this case, the four-point irregular star becomes even more irregular (Fig. 10e).

\section{Verification of the six-point irregular star polygon}

It was found appropriate to convert the six-point irregular star formed in rule 9 to six-point regular star for verification. All the arm lengths of the six-point star were made equal in length and at the same time, all arms were converted into isosceles triangles. In this case, some arms of the six-point stars cannot touch with neighboring stars and the gaps remain between the arms (Fig. 10f).

In order to maintain the six-point star regular, the arms of neighboring stars can be changed. But, in this case, the five-point regular star, which is the neighboring star, becomes irregular. Changes should also be made in the arms of the eight-point irregular star (Fig. 10g).

\section{Verification of the eight-point irregular star polygon}

In rule 10, it was mentioned about an eight-point irregular star. The eight-point star is called irregular because it differs from the classical star format. However, it has symmetry and consistency in itself. A striking point in this star is the relationship between the polygon in the middle of the star and the frame of the muqarnas plan. The edge of the frame is at the centroid of the polygon.

An experiment was made by transforming the eightpoint irregular star into a regular star format defined by isosceles triangles. However, in this case, the relationship between the polygon in the middle of the eightpoint regular star and the frame was distorted. The edge of the frame does not fit to the centroid of the polygon (Fig. 10h).

Preserving the eight-point regular star, the edge of the frame was moved to the centroid of the polygon in the middle of this eight-point star. But, in this case, due to the growth of the frame, different parts are beginning to be included in the plan. This situation does not match the plan view obtained with laser scanning (Fig. 10i).

\section{The plan formation of muqarnas at Sehzade Mosque main gate}

The plan formation of muqarnas at Sehzade Mosque main gate was examined within the framework of the shape grammar theory. The rule-based examination of the forms is given in Figs. 11, 12, 13, 14 and Additional file 2: Movie S2, and the detailed explanation of the rules is listed below. 

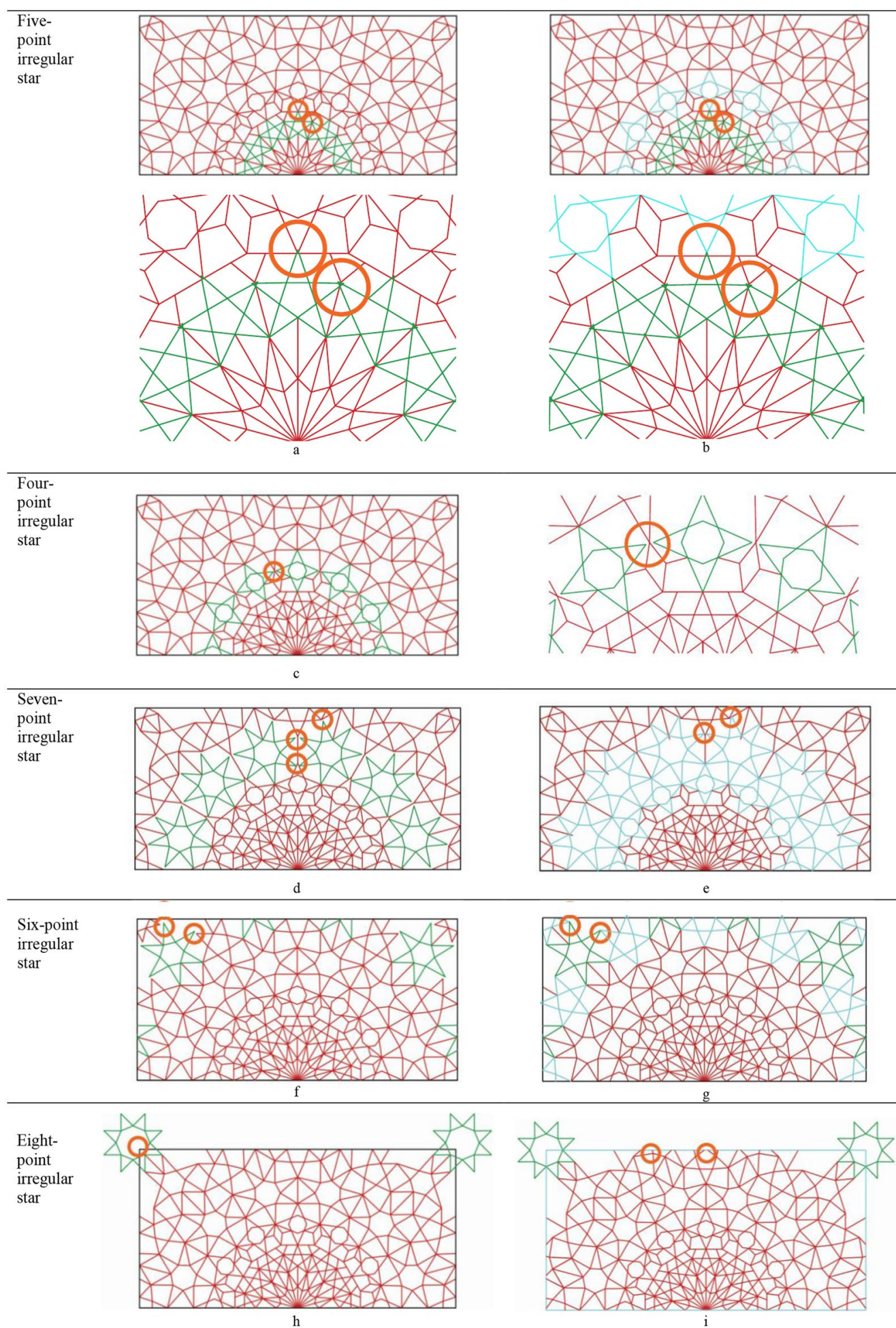

Fig. 10 The regular states of the irregular stars in the muqarnas plan of Mihrimah Sultan Mosque main gate and the emerging problems accordingly 

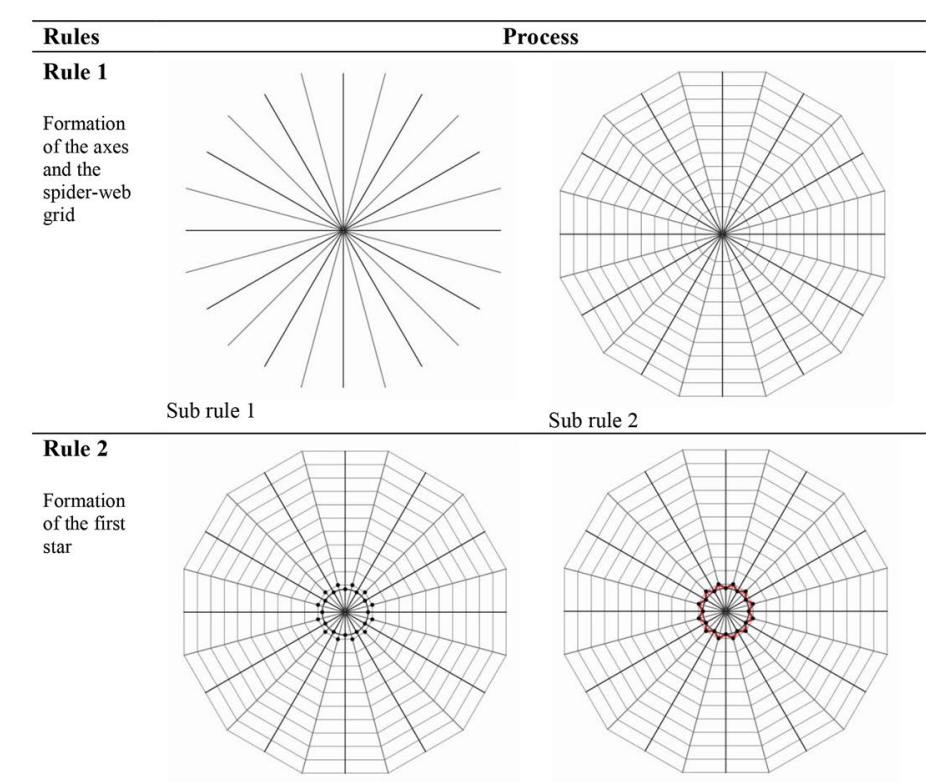

Sub rule 2
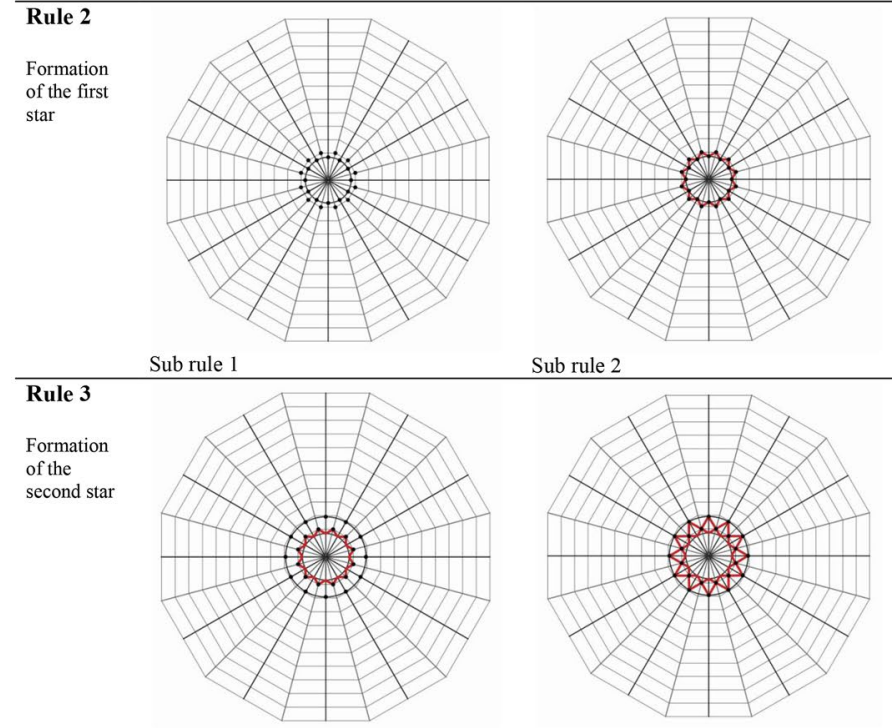

Sub rule 2
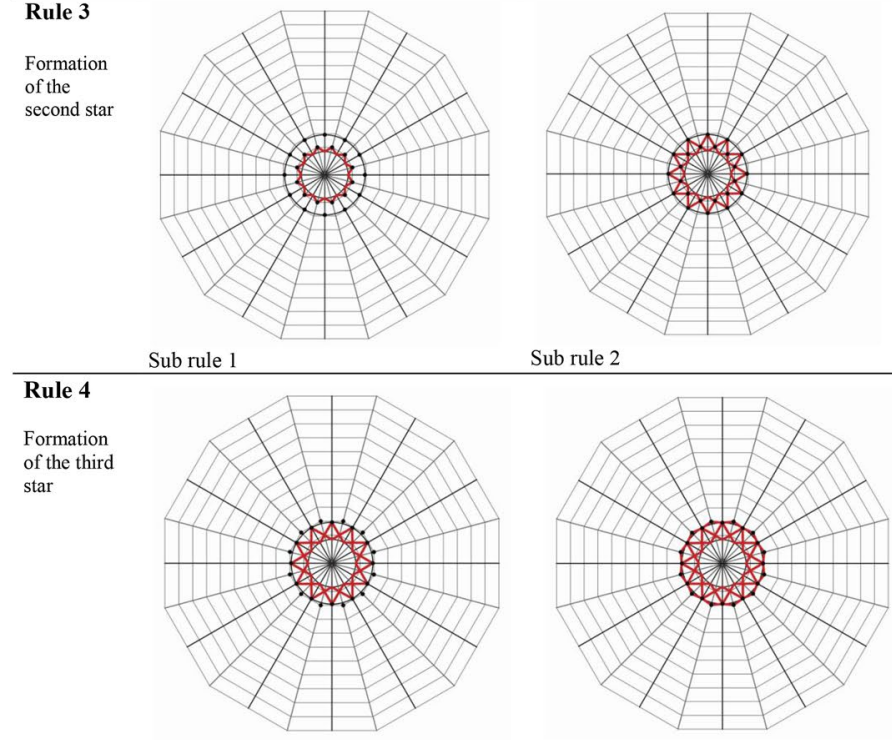

Sub rule 2

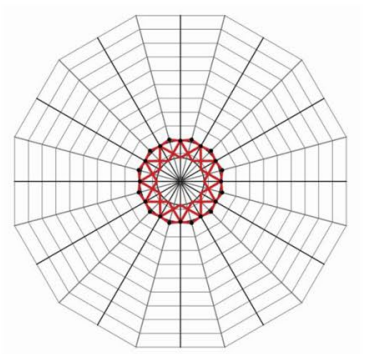

Sub rule 1

Sub rule 2

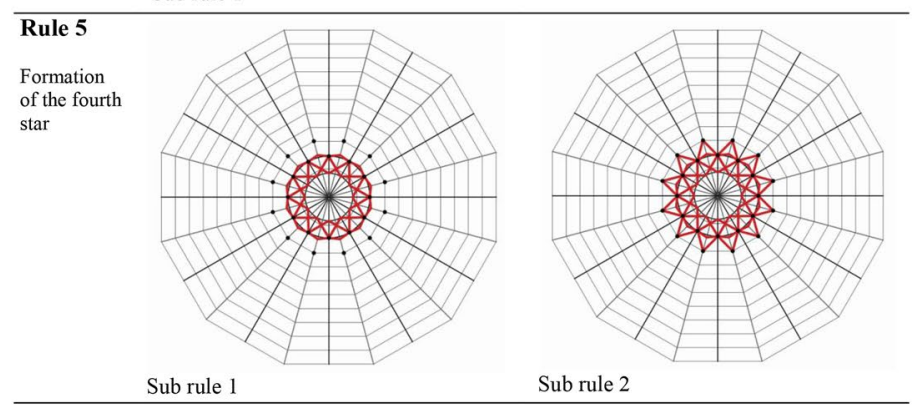

Fig. 11 Analysis of the muqarnas plan of Sehzade Mosque main gate (rule 1 to rule 5) 


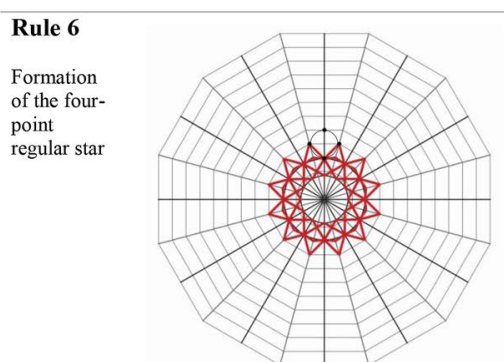

Sub rule 1

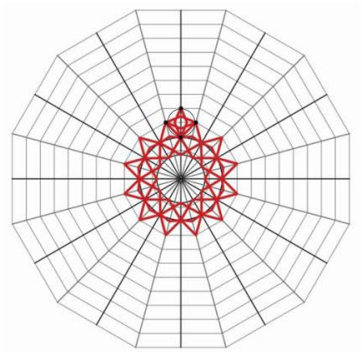

Sub rule 3

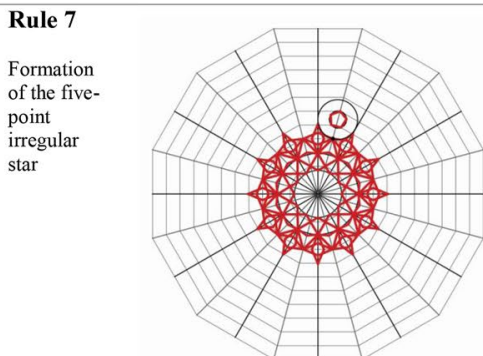

Sub rule 1

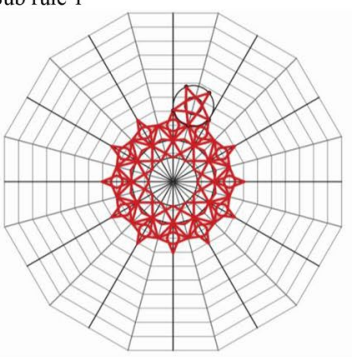

Sub rule 3

Rule 8

Formation

of the

surrounding

circle

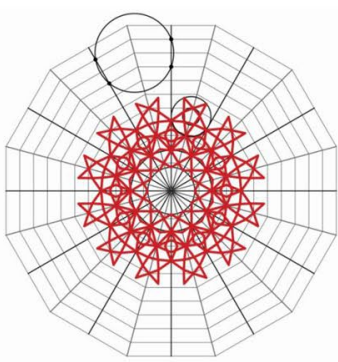

Sub rule 1

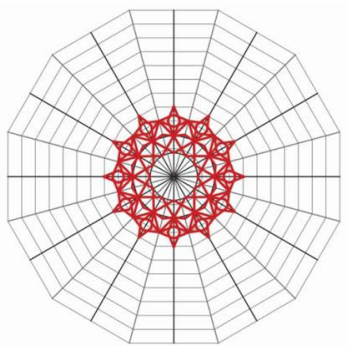

Sub rule 4

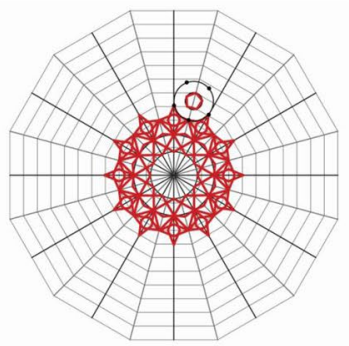

Sub rule 2

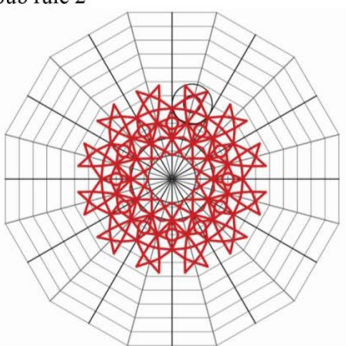

Sub rule 4

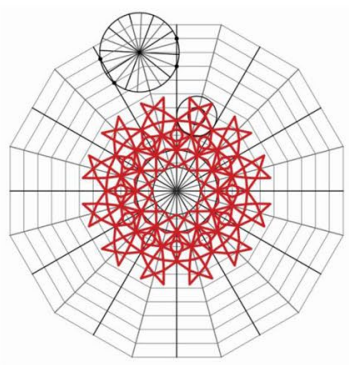

Sub rule 2

Fig. 12 Analysis of the muqarnas plan of Sehzade Mosque main gate (rule 6 to rule 8) 


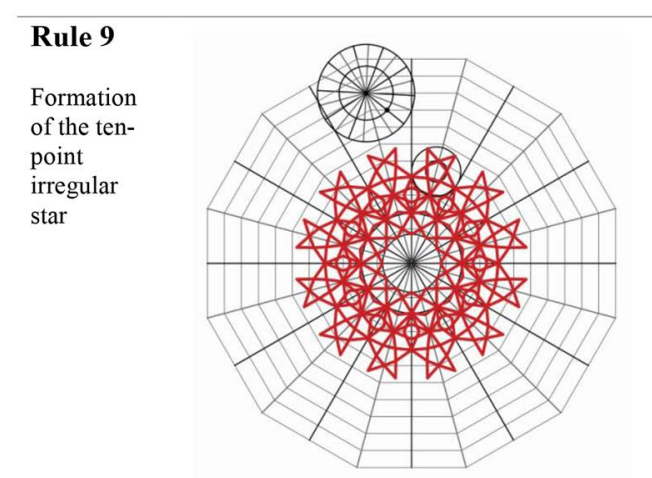

Sub rule 1
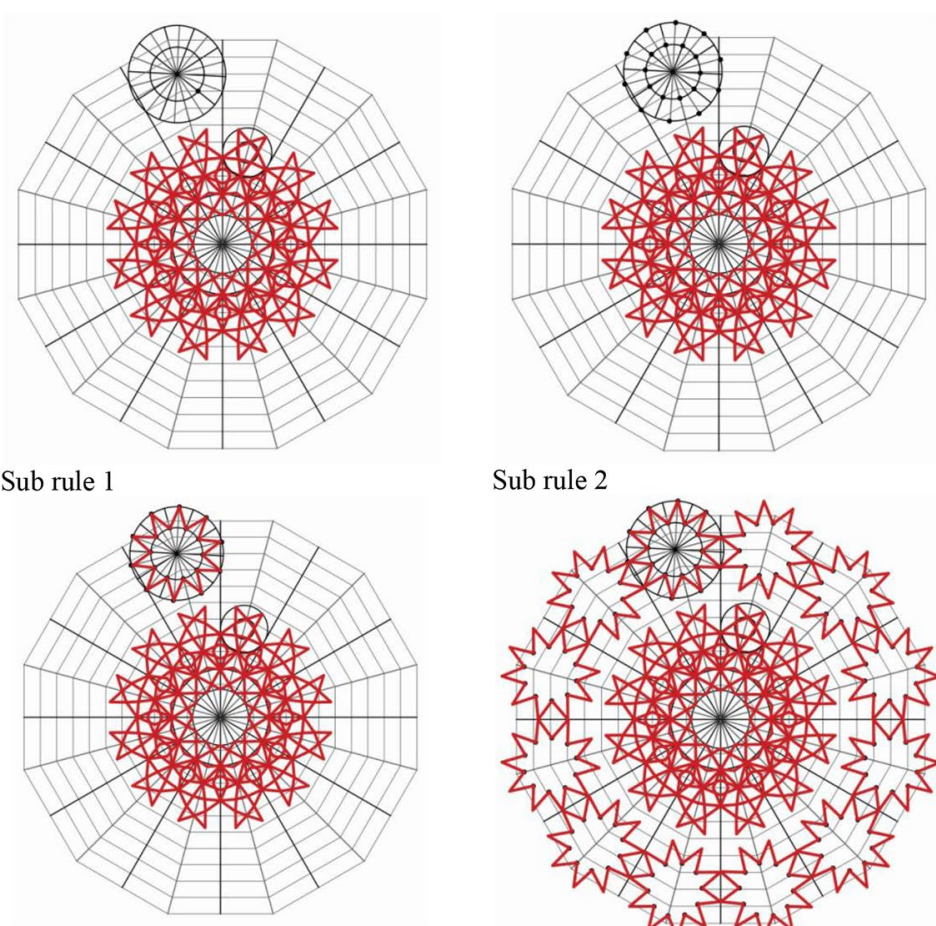

Sub rule 2

Sub rule 3

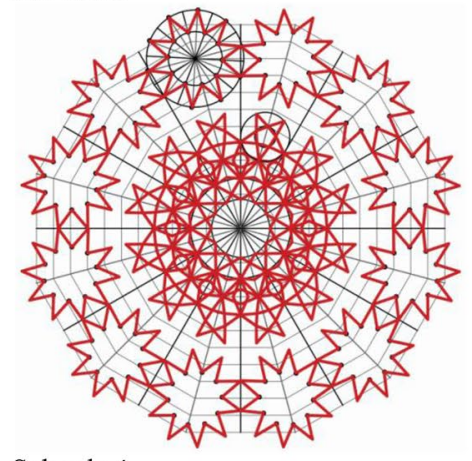

Sub rule 4
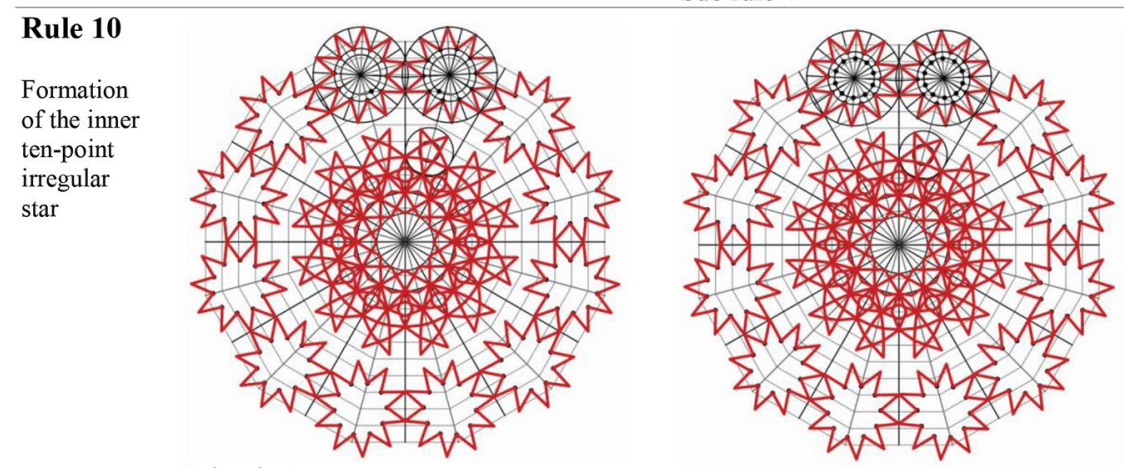

Sub rule 1

Sub rule 2

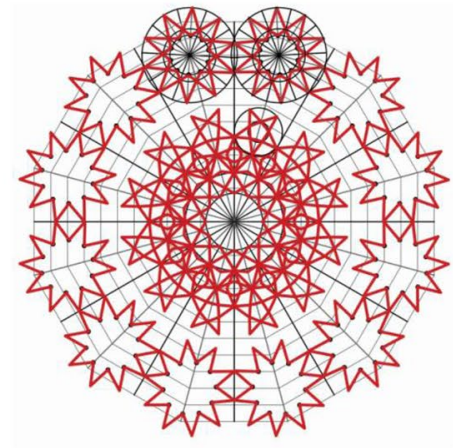

Sub rule 3

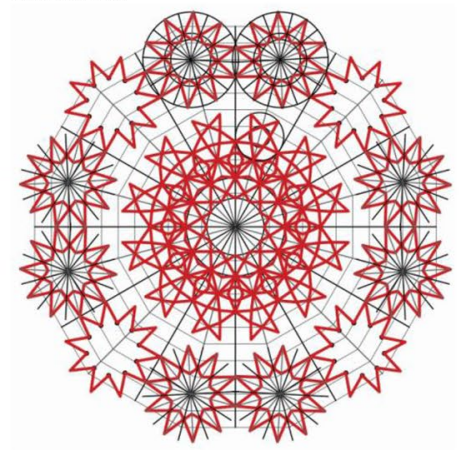

Sub rule 4

Fig. 13 Analysis of the muqarnas plan of Sehzade Mosque main gate (rule 9 and rule 10) 

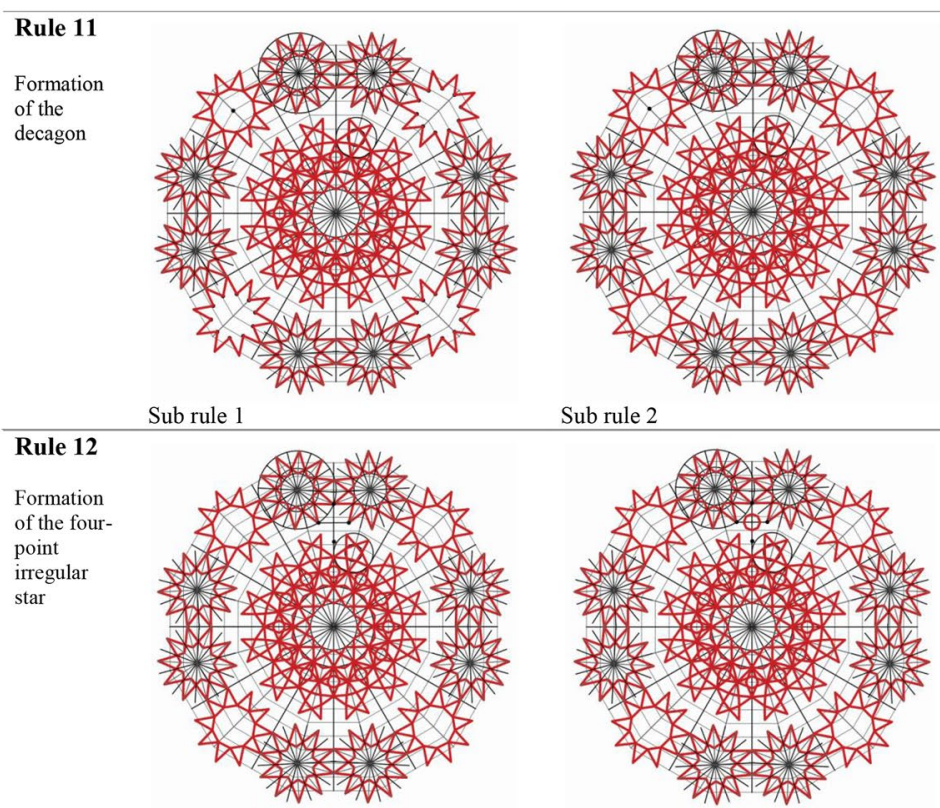

Sub rule 2

Sub rule 1

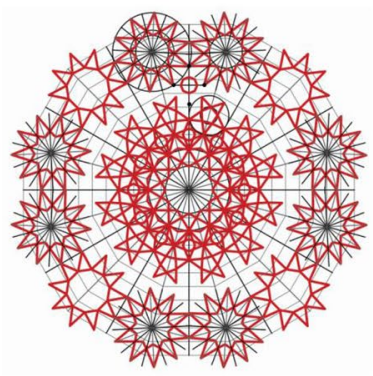

Sub rule 2
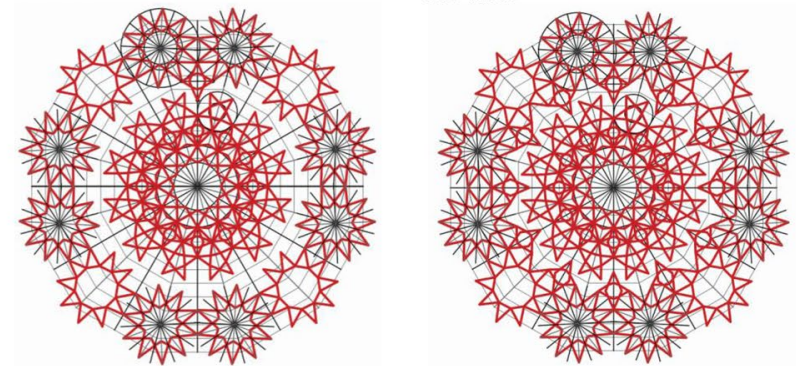

Sub rule 3

Sub rule 4
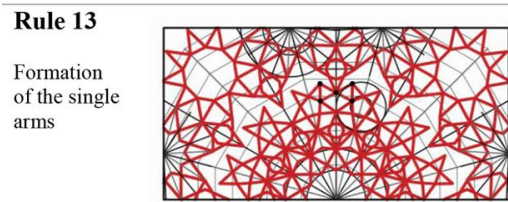

Sub rule 1
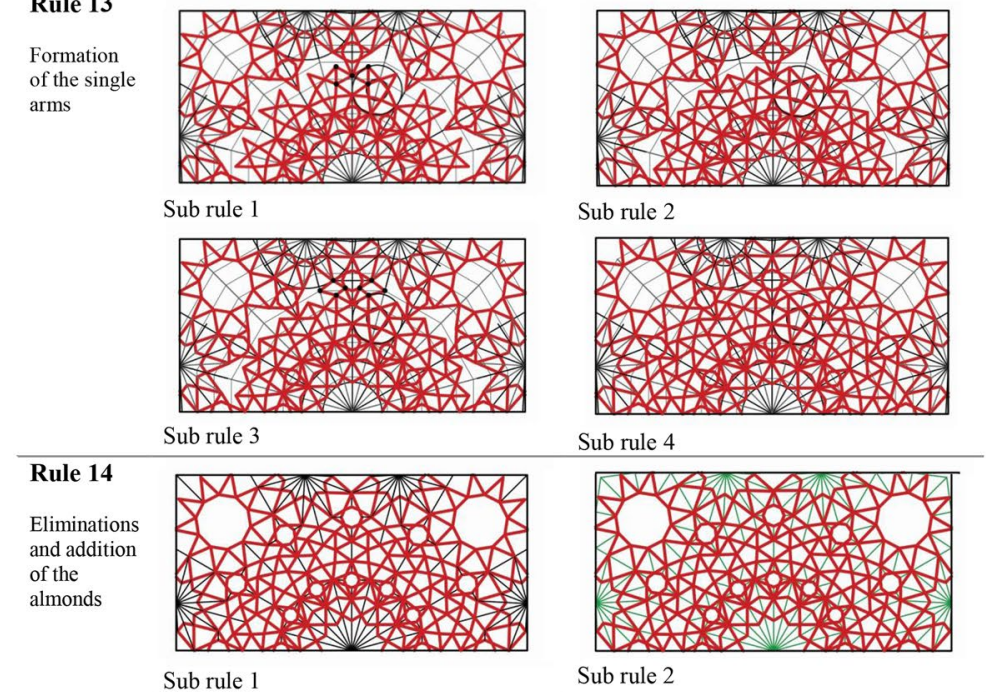

Sub rule 3

Sub rule 2

Fig. 14 Analysis of the muqarnas plan of Sehzade Mosque main gate (rule 11 to rule 14) 
- First of all, the main axes were formed such that the angle between them was $30^{\circ}$. Afterwards, intermediary axes (rule 1 , sub rule 1 ) were created such that the angle between them was $15^{\circ}$. A radial grid system, similar to the spider-web, was created at equal intervals with reference to these axes (rule 1 , sub rule 2).

- To create the first star, a circle was created in the center of the spider-web grid. The intersection points of this circle with the main axes and the intersection points of the first strip of the spider-web grid with the intermediary axes were determined (rule 2, sub rule 1). Afterwards, the first star was created via forming lines between these points (rule 2, sub rule 2).

- For the second star formation, the intersection points of the second strip of the spider-web grid with the main axes were determined (rule 3, sub rule 1). By creating lines between these points and the points on the first strip of the spider-web grid used in the formation of the first star, second star was created (rule 3 , sub rule 2 ).

- For the formation of the third star, the intersection points of the second strip of the spider-web grid with the intermediary axes were determined (rule 4, sub rule 1). By creating lines between these points and the points on the main axes determined in the second star formation, third star was created (rule 4, sub rule 2).

- For the fourth star formation, the intersection points of the third strip of the spider-web grid with the intermediary axes are determined (rule 5 , sub rule 1 ). By creating lines between these points and the points on the main axes determined in the formation of the second star, the fourth star was created (rule 5, sub rule 2).

- For the formation of four-point regular star in rule 6, a circle was created based on the intersection points determined on the second and third strip of the spider-web grid (rule 6, sub rule 1). An inner circle was drawn inside of the circle with reference to the third strip of the spider-web grid. An octagon, the centroid of which was on the main axle, was placed inside of the inner circle (rule 6, sub rule 2). The lines between the points determined on the strips of the spider-web grid and the octagon were formed. Thus, a four-point regular star was created (rule 6 , sub rule 3). This star was replicated into 12 arranged in circular formation with reference to the origin point (rule 6, sub rule 4).

- For the five-point irregular star formation in rule 7, a circle was created based on the three intersection points determined on the third and fourth strips of the spider-web grid (rule 7, sub rule 1). Then, a pen- tagon was placed so that its edges intersect with the fourth and fifth strips of the spider-web grid, and its center was on the intermediary axle (rule 7 , sub rule 2). The three arms of the star were created via forming lines between the points on the third and fourth strip of the spider-web grid and the corresponding edges of the pentagon. The other two arms of the star were formed as isosceles triangles in relation to the pentagon and the circle (rule 7, sub rule 3 ). The obtained five-point irregular star was replicated into 12 arranged in circular formation with reference to the origin point (rule 7, sub rule 4). Thus, five-point irregular star formation was completed. Here it is noteworthy that the stars are lined up on a strip.

- Rule 8 is the stage of creating the circle that we define as the surrounding circle, which will be the base for the ten-point irregular star. First, a circle was formed from the intersection points of the eighth and tenth strips of the spider-web grid with the corresponding main axes (rule 8 , sub rule 1). Afterwards, from the circle center, the main axes with the $36^{\circ}$ angle between them and the intermediary axes with the $18^{\circ}$ angle between them were formed (rule 8, sub rule 2). The formation of the ten-point irregular star and its base works differently from the spider-web grid system. But it can be seen in the final version of the plan that this star also receives references from the spiderweb grid.

- In rule 9, a ten-point irregular star was created with reference to the surrounding circles. First, an inner circle was determined in the surrounding circle (rule 9 , sub rule 1 ). Then, the intersection points of the inner circle with the main axes and the outer circle with the intermediary axes were determined (rule 9, sub rule 2). By forming lines between these points, a ten-point regular star (the star with equal edge lengths) was obtained (rule 9, sub rule 3). This star was replicated into 12 arranged in circular formation. But when it was replicated circularly, the arms of the stars did not touch each other. In order to stick to the original version of the plan, two arms of the ten-point regular stars were slightly extended, so that the arms of the stars were touching each other on the strip of the spider-web grid. Thus, ten-point irregular star was obtained (rule 9, sub rule 4).

- In rule 10 , within the stars created in the previous stage (in the surrounding circles), an inner ten-point regular star was created. For this process, two surrounding circles were selected and inner circles were created inside of these circles (rule 10, sub rule 1 ). The intersection points of the inner circles with the intermediary axes were determined (rule 10, sub rule 2 ). By creating lines between these points, an inner 
ten-point regular star was obtained (rule 10, sub rule 3 ). This obtained star was duplicated via copying it to the relevant parts (rule 10, sub rule 4).

- In rule 11, the inner part for the remaining four surrounding circles was formed. For this, a decagon was obtained in the star (rule 11, sub rule 1). This decagon was replicated into four arranged in circular formation (rule 11 , sub rule 2 ).

- In rule 12, a four-point irregular star was created. A line was determined by referring to the related arms of the ten-point irregular stars (rule 12, sub rule 1). An octagon was formed at the intersection of this line with the main axle (rule 12, sub rule 2 ). The fourpoint irregular star was shaped around this octagon. At the same time, the three arms of this star intersect with the corresponding arms of the ten-point irregular star. The four-point irregular star has two arms in equal length and the other two arms also in equal length (rule 12, sub rule 3 ). The obtained fourpoint irregular star was replicated into 12 arranged in circular formation with reference to the origin point (rule 12, sub rule 4).

- In rule 13, half of the pattern was eliminated and the geometry of the muqarnas plan was obtained. The first single arms were added to the space between the five-point irregular star and the four-point irregular star (rule 13, sub rule 1). These single arms were duplicated circularly (rule 13, lower rule 2). Then the second single arms were added (rule 13, sub rule 3). These single arms were also duplicated circularly (rule 13 , sub rule 4 ).

- Finally, the grid and the axes were eliminated (rule 14 , sub rule 1 ). The whole muqarnas plan composition was obtained by adding almonds (rule 14, sub rule 2).

\section{Verification of the muqarnas plan form at Sehzade Mosque main gate Verification of the five-point irregular star polygon}

It was found appropriate to convert the five-point irregular star mentioned in rule 7 in the rule set, to five-point regular star for verification. The arms of the five-point irregular star were converted to isosceles triangles in relation to the pentagon in the center of the star. In this case, the problems occured in the areas between the stars. The arms of the five-point stars do not touch the neighboring four-point stars in the lower part, and the gaps remain between the arms (Fig. 15a).

Preserving the five-point regular star form, it was tried to change the lengths of the other star-arms that are in relation to the five-point star. In this case, the arm lengths of the four-point stars must be modified to fill the gaps. Thus, the modified four-point stars become irregular. One arm length of the four-point stars becomes in different length from the other three arms (Fig. 15b).

\section{Verification of the ten-point irregular star polygon}

It was found appropriate to convert the ten-point irregular star mentioned in rule 9 in the rule set, to ten-point regular star for verification. If a ten-point regular star (all arms in equal length) is replicated, overlaps occur in one of the arms (Fig. 15c).

Preserving the ten-point regular star form, the overlapping arms were prevented to be overlapped for verification. In this case, the lengths of all arms were slightly shortened. Other problems arose when the arms were shortened. One of the problems is that the relationship of ten-point stars with four-point stars at the lower part was interrupted. Another problem is that the relationship between the reciprocally touching arms of the ten-point stars was interrupted. These cross-touching arms are significant since they are located on a strip of the spiderweb grid and are the dominant focus of the composition (Fig. 15d).

\section{Verification of the four-point irregular star polygon}

It was found appropriate to convert the four-point irregular star mentioned in rule 12 in the rule set, to four-point regular star for verification. When the four-point irregular star was converted to regular star, its relationship with ten-point stars was interrupted and the gaps were formed (Fig. 15e).

When the four-point irregular stars were converted to the regular stars, the positions of the arms of the ten-point stars can be slightly changed to resolve the gaps formed between the four-point stars and the tenpoint stars. However, when the ten-point star arms were slightly displaced, the ten-point stars become very irregular (Fig. 15f). Therefore, it is thought that the ten-point star arms, which will be of very different lengths, are not suitable for the plan composition.

\section{The plan formation of muqarnas at Suleymaniye Mosque main gate}

The plan formation of muqarnas at Suleymaniye Mosque main gate was examined within the framework of the shape grammar theory. A rule-based examination of the forms is given in Figs. 16, 17, 18 and Additional file 3: Movie S3 and detailed explanation of the rules is listed below.

- For the geometric analysis of the selected muqarnas plan, a square grid system was created with vertical and horizontal axes that have equal angles between 

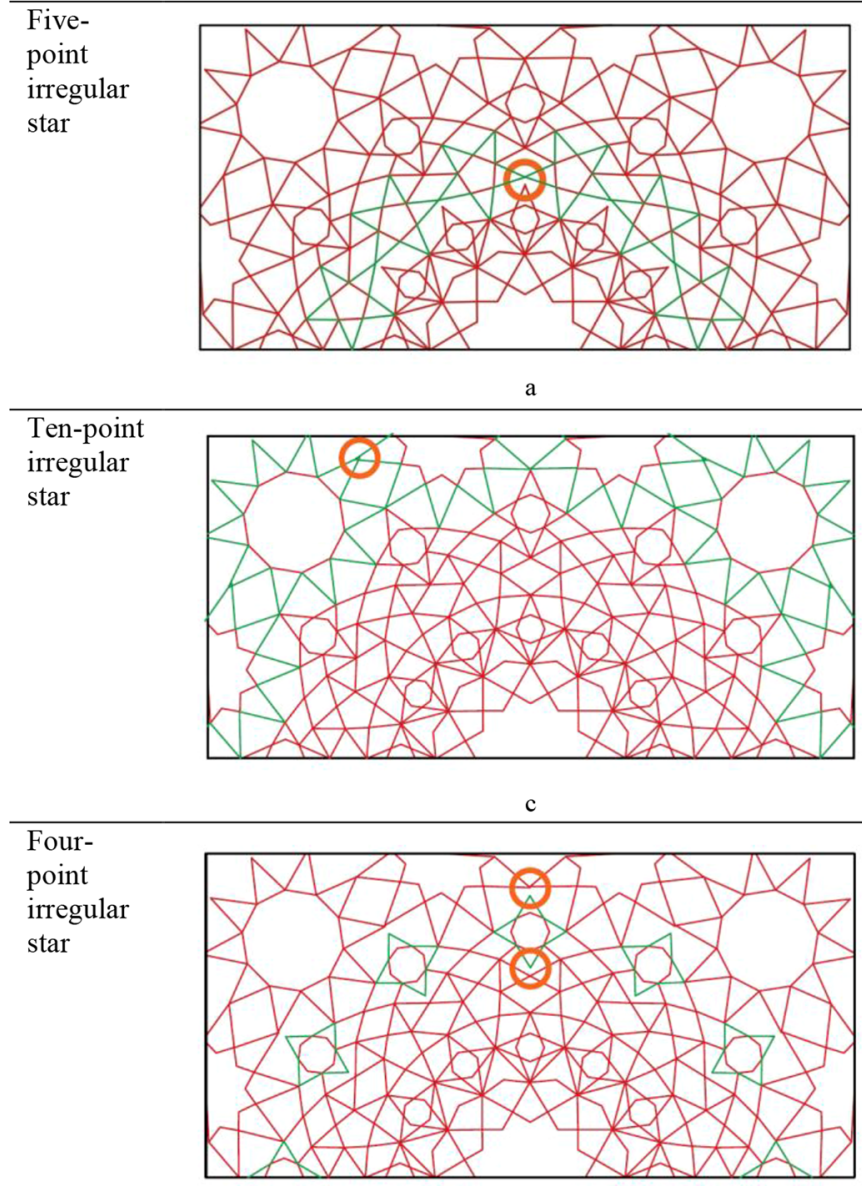

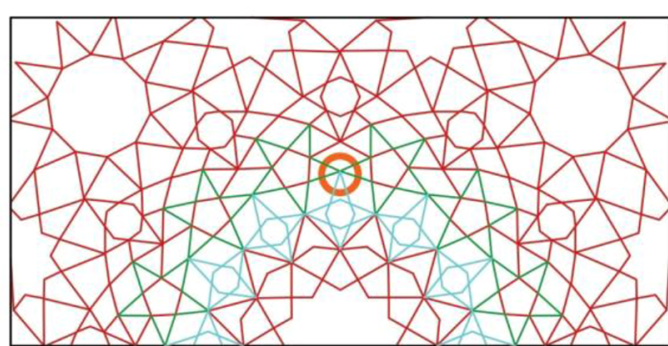

b

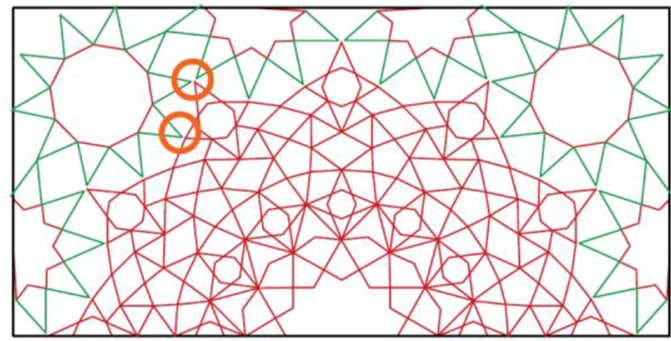

$\mathrm{d}$

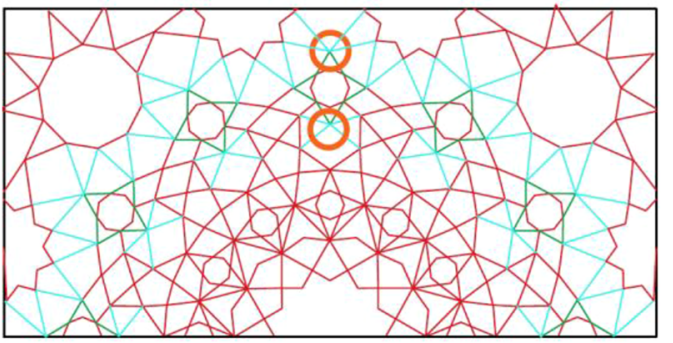

f

Fig. 15 The regular states of the irregular stars in the muqarnas plan of Sehzade Mosque main gate and the emerging problems accordingly

them (rule 1, sub rule 1). Circles of equal size were placed at the intersection points of the vertical and horizontal axes (rule 1, sub rule 2).

- The main axes were placed in the center of the one of the circles with $45^{\circ}$ angle between them. Intermediary axes were formed with an angle of $22.5^{\circ}$ to the main axes (rule 2, sub-rule 1). This axle module formed was copied to all circle centers (rule 2, sub rule 2).

- For the creation of the unity in the square grid system, the main axes were copied such that they extended beyond the grid (rule 3 , sub rule 1 ). Then the axes outside the frame of the main square grid system were eliminated (rule 3 , sub rule 2).

- To create a star module in rule 4, a polygon was placed inside the circle (rule 4, sub rule 1). In order to form star arms inside the polygon, another inner circle was created (rule 4, sub rule 2). Then, the intersection of the polygon with intermediary axes and the intersection of the inner circle with the main axes were determined (rule 4, sub rule 3). Later, lines between these points were formed and an eight-point regular star was created (rule 4, sub rule 4).

- To create another star in rule 5, an inner circle was created in the circle based on the same center point (rule 5 , sub rule 1 ). The intersection points between this circle and the intermediary axes were determined (rule 5, sub rule 2). The second eight-point star was created via forming lines between these points and the points determined in the previous star formation (rule 5, sub rule 3). The created star module was copied inside of all the circles (rule 5 , sub rule 4).

- In rule 6 , the second grid system was formed. The circles were placed in the internal spaces formed between the main axes of a module of the square grid (rule 6, sub rule 1). The formed radial circle unit was copied to the whole system (rule 6, sub rule 2).

- In rule 7, a five-point irregular star was formed inside a circle in the second grid system with reference to 


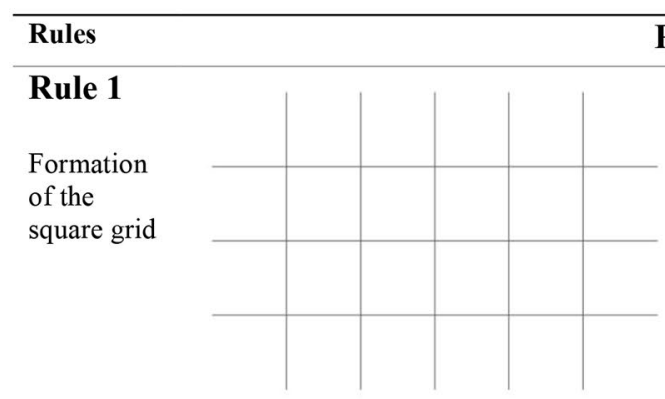

Sub rule 1

\begin{tabular}{l}
\hline Rule 2 \\
$\begin{array}{l}\text { Formation } \\
\text { of axes }\end{array}$
\end{tabular}

Sub rule 1

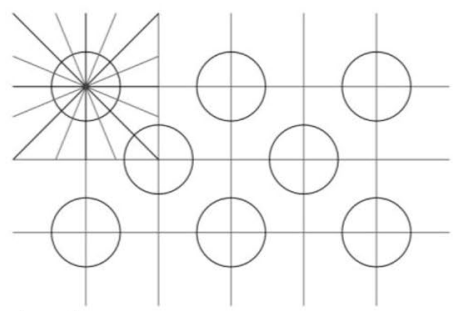

Rule 3
Formation
of axes
beyond the
grid

\section{Sub rule 1}

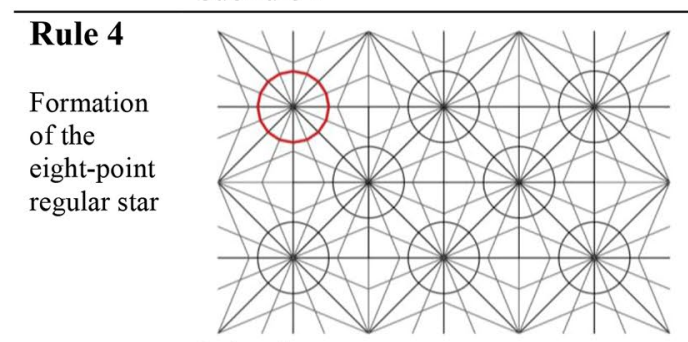

Sub rule 1

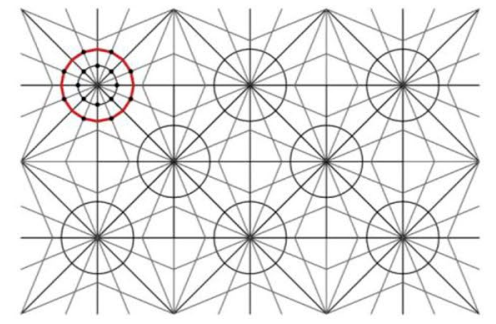

Sub rule 3

\section{Process}

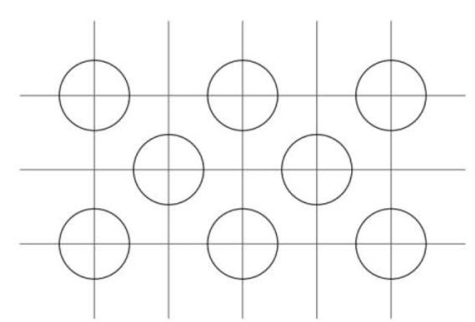

Sub rule 2

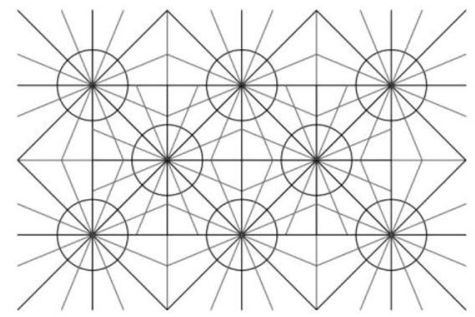

Sub rule 2

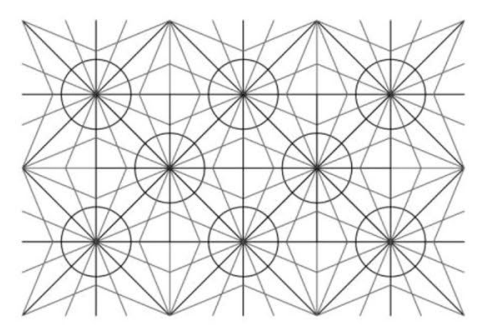

Sub rule 2

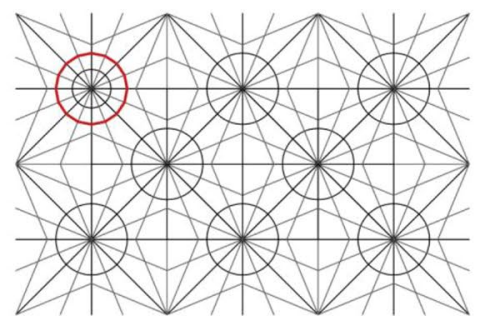

Sub rule 2

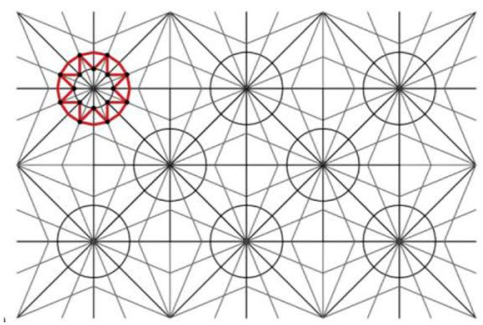

Sub rule 4

Fig. 16 Analysis of the muqarnas plan of the Suleymaniye Mosque main gate (rule 1 to rule 4) 


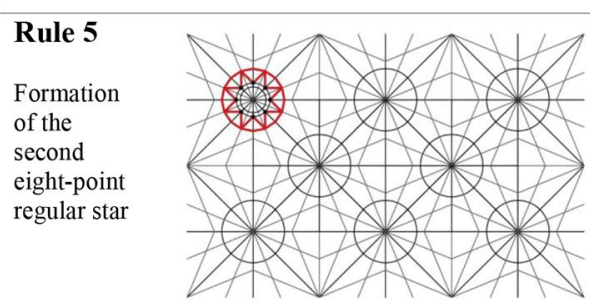

Sub rule 1

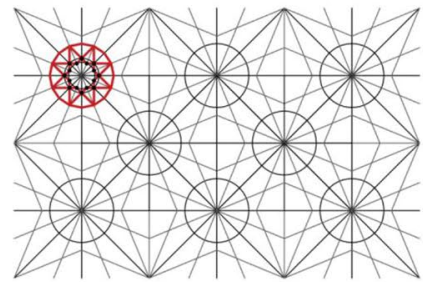

Sub rule 3

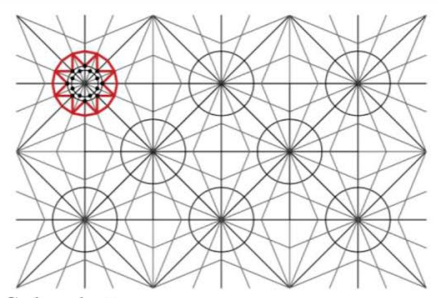

Sub rule 2

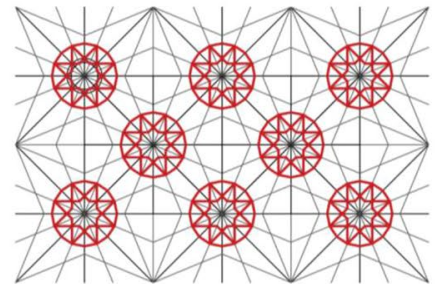

Sub rule 4

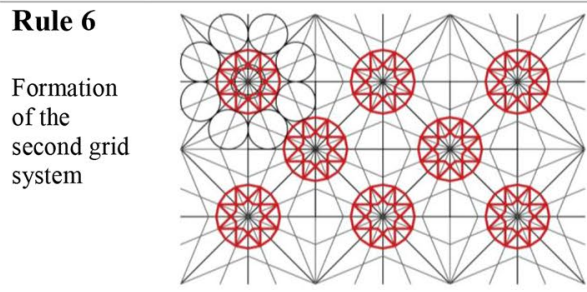

Sub rule 1

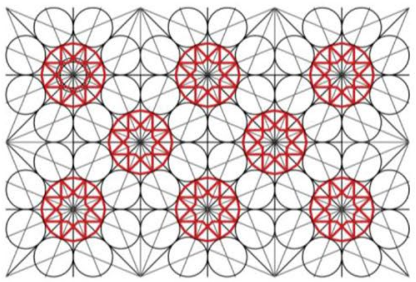

Sub rule 2
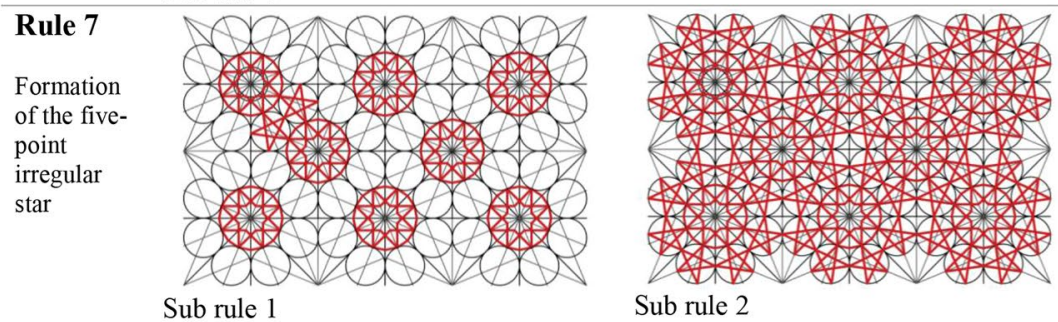

Rule 8

Formation

of three-

point star

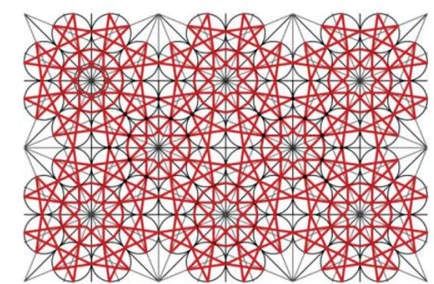

Sub rule 1

Sub rule 2

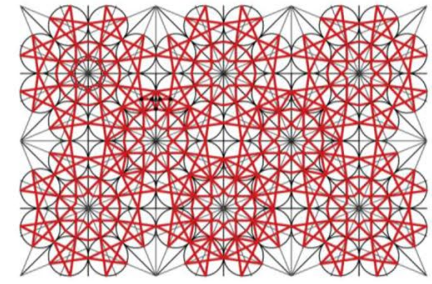

Sub rule 3

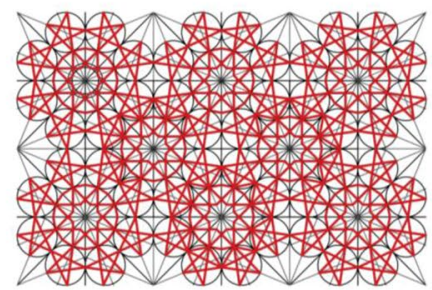

Sub rule 2

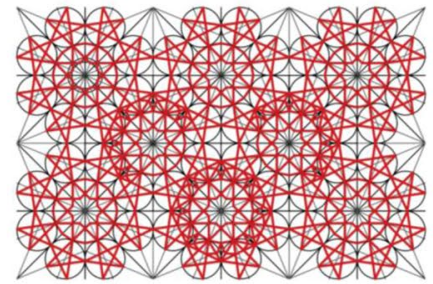

Sub rule 4

Fig. 17 Analysis of the muqarnas plan of the Suleymaniye Mosque main gate (rule 5 to rule 8) 


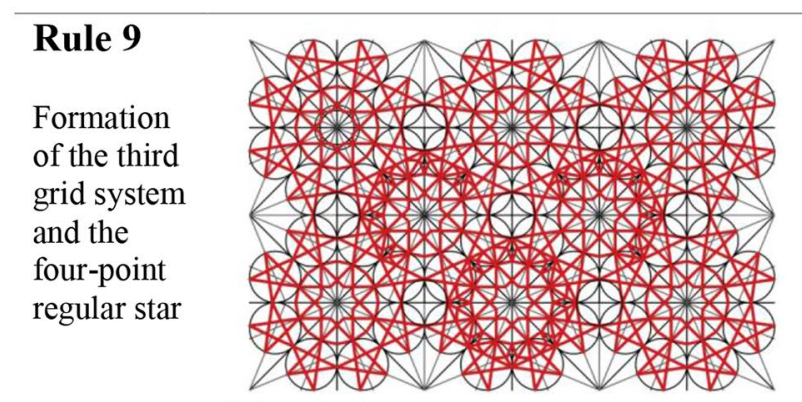

Sub rule 1

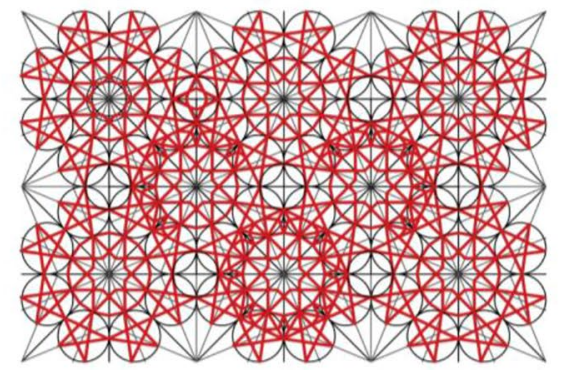

Sub rule 3

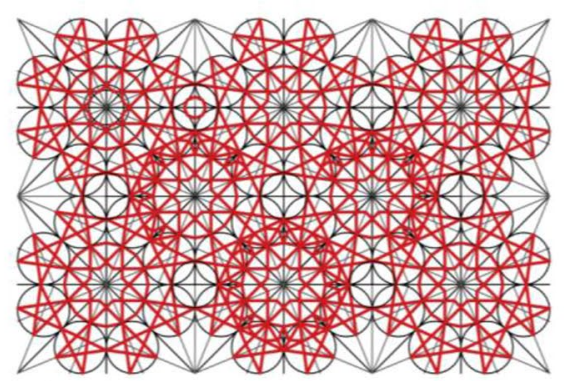

Sub rule 2

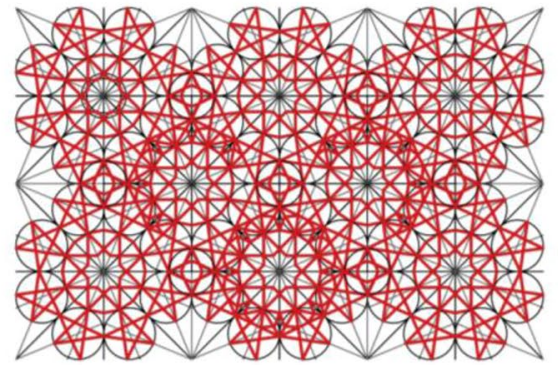

Sub rule 4

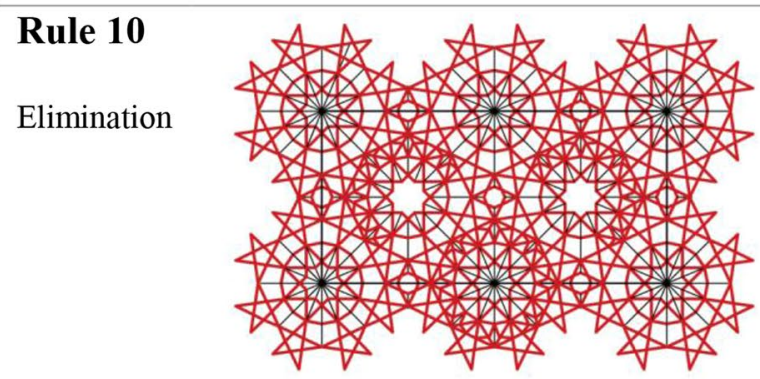

Sub rule 1

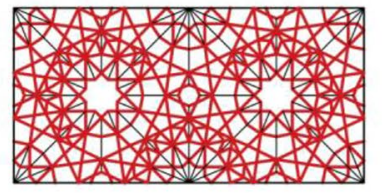

Sub rule 2

\section{Rule 11}

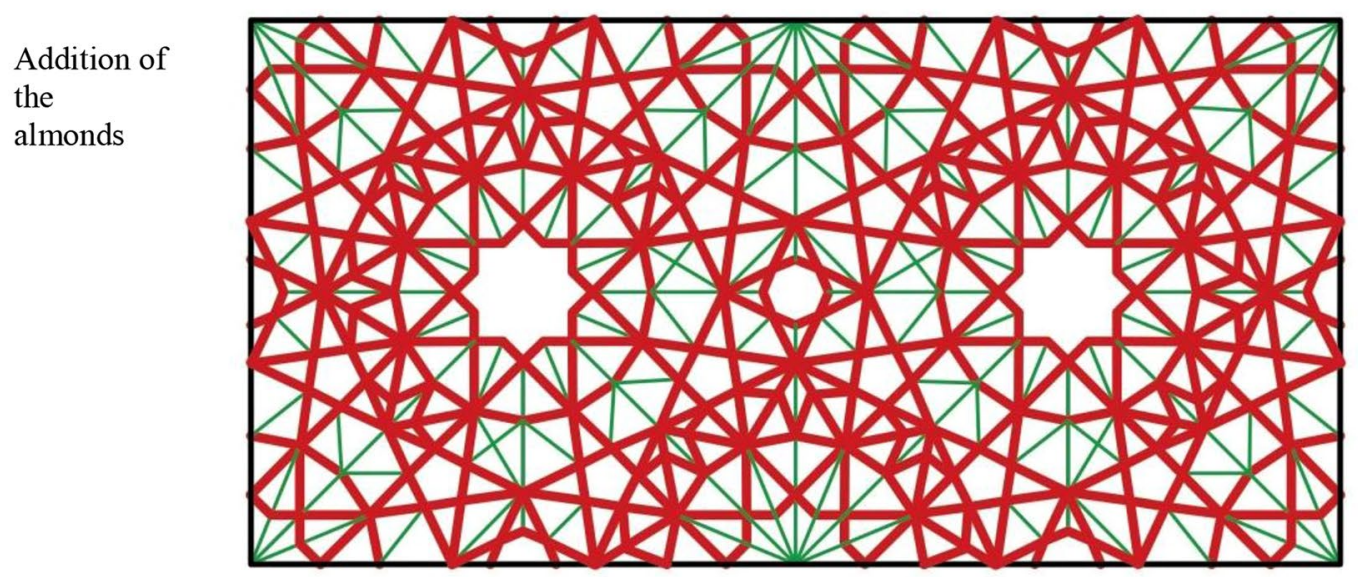

Fig. 18 Analysis of the muqarnas plan of the Suleymaniye Mosque main gate (rule 9 to rule 11) 
the arms of the eight-point stars. This star was mirrored to the second grid unit next to it (rule 7, sub rule 1). The obtained two five-point irregular stars were replicated in circular formation with reference to the square grid unit center. Five-point irregular stars were placed in the whole system (rule 7 , sub rule 2).

- In rule 8 , the points were determined to form threepoint stars (rule 8 , sub rule 1). The lines were formed between these points (rule 8 , sub rule 2). Later, a three-point star module was created (rule 8 , sub rule 3 ). The created three-point star module was copied over the relevant parts (rule 8, sub rule 4).

- Rule 9 is related to the four-point regular stars which were formed in between the five-point irregular stars. First, the circles associated with the five-point star arms were formed at the intersections of the horizontal and vertical main axes of the square grid (rule 9, sub rule 1). These circles form the third grid system. An inner circle, which is in relation to the second grid system, was formed inside of a circle of the third grid system and an octagon was placed in it (rule 9, sub rule 2). Then, the lines between the end points of the arms of the five-point irregular stars and the octagon center were formed, and the arms of four-point star were obtained (rule 9, sub rule 3). The obtained fourpoint regular star was copied to the units of the third grid system (rule 9 , sub rule 4). Thus, the formation of four-point regular star was completed.

- In rule 10, the grids and unnecessary axes were eliminated (rule 10, sub rule 1). Then, the geometry of the muqarnas plan was obtained by cropping the pattern (rule 10 , sub rule 2 ).

- Finally, in rule 11, the whole muqarnas plan composition was obtained by adding almonds (rule 11).

\section{Verification of the muqarnas plan form at Suleymaniye Mosque}

It was found appropriate to convert the five-point irregular star mentioned in rule 5 in the rule set, to five-point regular star for verification. In the first verification, the positions of the pentagons in the centers of the five-point irregular stars were preserved, and all of the arms of the five-point irregular stars were brought to the same length. As a result, it was observed that overlapping of some arms and the gaps were formed in some areas (Fig. 19a).

In the second verification, the pentagons in the centers of the five-point stars were slightly displaced and the star arms were kept in equal length. As a result, the relationship between the arms of the five-point stars and the arms of the eight-point stars was disrupted (Fig. 19b).
In the third verification, in addition to what was done in the previous verification, an alternative was produced for the region where the five-point stars arms should touch the arms of the eight-point stars. The star arms in this region were modified. However, the arms moved away from the isosceles triangle geometry and the result was contrary to the plan composition (Fig. 19c, d).

\section{Conclusion}

The difference in the dimensions of the star arms may be due to the decision of the architect/master during the implementation of the design. However, the results of the analysis and orthophotos found at the end of scans showed that the irregular arms of the stars are symmetrical and they are identical. Also, the irregular arms of a star are identical with the arms of the stars in the same row (same layer in 3D). It requires the architect to carefully repeat this detailed measurement at each layer. Furthermore, according to the analysis we made, it has been revealed that, if the lengths of the arms are equal, the points of the arms of stars cannot touch each other in a systematic way. Therefore, in the plan drawings it is not possible for star arms to be equal mathematically.

It was concluded that the main gate muqarnas plan compositions of Mihrimah Sultan Mosque and Sehzade Mosque are similar to each other. A similar spider-web grid was used in both plans, and the star arms were dominantly arranged on the strips of the spider-web grid. When we look at the front views of the main gates of these mosques obtained from laser scanning, it is seen that the muqarnas are also similar in terms of having vertical long spanning with multilayers. Considering that the construction dates of these mosques, one of which was built in the name of Suleiman the Magnificent's son and the other was built in the name of his daughter, are almost the same, so that it can be concluded that the muqarnas designer/master is the same.

As a result of the layouts of the main gate muqarnas of the Mihrimah Sultan Mosque and the main gate muqarnas of the Sehzade Mosque based on spider-web grid, it can be said that some star arms in the composition are shaped according to this spider-web grid. For this reason, star arms are not equal in some cases.

In this study, the spider-web grid, which was used as a layout for the main gate muqarnas of the Mihrimah Sul$\tan$ Mosque and the main gate muqarnas of the Sehzade Mosque, was created with equal intervals. However, the spider-web grid can also be created with unequal intervals or with more dense intervals. Each version has the same logic and is a spider-web system.

It has been revealed in the analysis and verifications that there are stars with unequal arm lengths in the main gate muqarnas plans of the Mihrimah Sultan Mosque and the Sehzade Mosque. When trying to create the same 


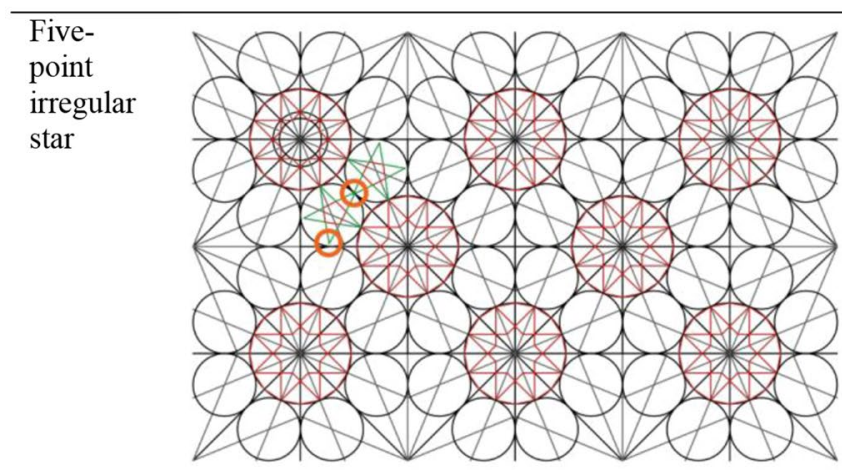

a

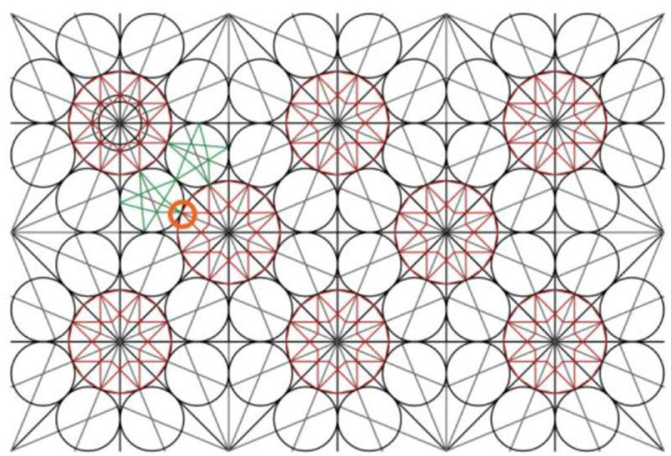

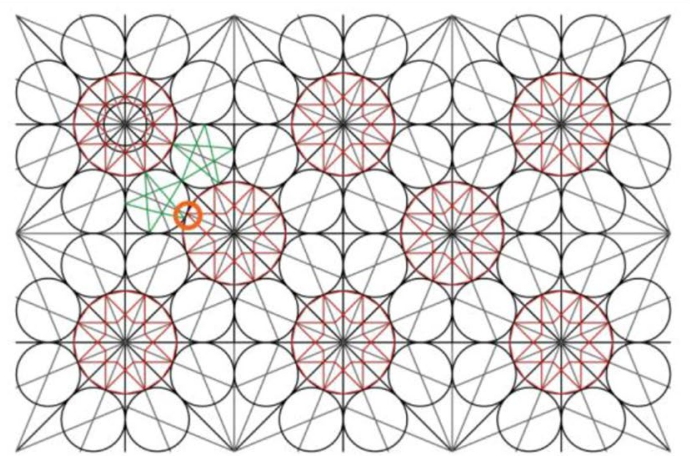

$\mathrm{b}$

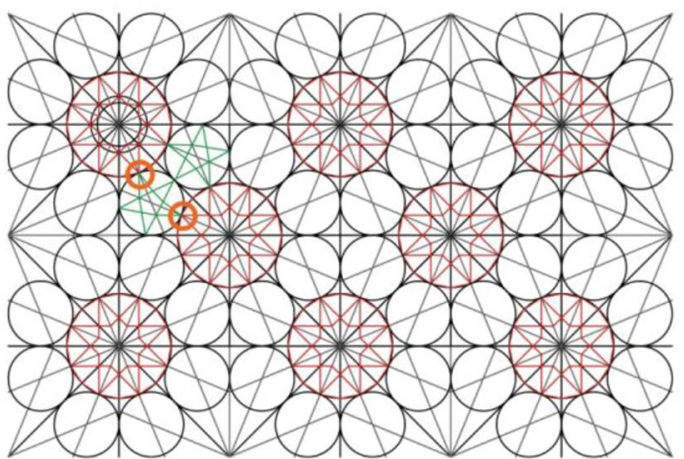

d

Fig. 19 The regular states of the irregular stars in the muqarnas plan of Suleymaniye Mosque main gate and the emerging problems accordingly

composition with the regular star instead of the irregular star, the layout of the other stars becomes inconsistent. The gaps begin to appear between the star arms and the star arms begin to overlap.

It has been concluded that the main gate muqarnas plan of the Suleymaniye Mosque is very different from the main gate muqarnas plans of the Mihrimah Sultan Mosque and the Sehzade Mosque. Although this plan seems to have a radial system at first glance, it was determined that it was produced from a square grid system. The first thing that this square grid system brings in mind is that it can create stars with equal arm lengths. However, as the result of our research, it was seen that the stars with unequal arm lengths could also be produced with this type of grid. Except the arm lengths of the five-point stars in the muqarnas plan of the Suleymaniye Mosque, the arm lengths of the other stars were equal. There are slight differences in the arm lengths of the five-point stars (to fit the grid system). Also, according to the muqarnas plan composition, the verifications show that it is not possible five-point irregular star to be regular.

Within the scope of our previous study, we concluded that the ellipse grid layout may have been used in the preparation of muqarnas plans. In this study, in addition to the ellipse grid layout, it was revealed that spider-web grid and square grid layouts could also be used while creating muqarnas plans. In these studies, the main gate muqarnas of Ottoman period mosques were examined. However, both examining the muqarnas plans in other periods such as the Seljuk period and examining the muqarnas in various other parts of the buildings will reveal the types of layouts that may have been used in plan compositions.

\section{Supplementary Information}

The online version contains supplementary material available at https://doi. org/10.1186/s40494-022-00647-z.

Additional file 1: Movie S1. Mihrimah Sultan Mosque Main Gate Muqarnas Plan Formation.

Additional file 2: Movie S2. Sehzade Mosque Main Gate Muqarnas Plan Formation.

Additional file 3: Movie S3. Suleymaniye Mosque Main Gate Muqarnas Plan Formation.

\section{Acknowledgements}

Not applicable.

\section{Authors' contributions}

AA: conceptualization, methodology, investigation, in situ analyses, formal analysis, writing, editing, supervision, visualization; GY: investigation, in situ 
analysis, experimental tests and analysis, visualization; MS: theoretical inputs, interpretation, writing, editing. All authors read and approved the final manuscript.

\section{Funding}

This research did not receive any funding

\section{Availability of data and materials}

Not applicable.

\section{Declarations}

\section{Competing interests}

The authors declare that they have no competing interests.

\section{Author details}

${ }^{1}$ Department of Architecture, Ozyegin University, Istanbul, Turkey. ${ }^{2}$ Institute of Graduate Studies, Fatih Sultan Mehmet Vakif University, Istanbul, Turkey.

\section{Received: 8 November 2021 Accepted: 7 January 2022}

Published online: 21 January 2022

\section{References}

1. Ozdural A. An analysis of the geometry of stalactites: Buruciye Medrese in Sivas. METU JFA. 1991;11:57-71.

2. Garofalo V. A methodology for Studying Muqarnas: the extant examples in Palermo. Muqarnas. 2010;27:357-406.

3. Bonner J. Islamic geometric patterns: their historical development and traditional methods of construction. New York: Springer; 2017.

4. Broug E. Islamic geometric patterns. London: Thames and Hudson; 2008.

5. Bourgoin J. Les Eléments de l'Art Arabe: Le Trait des Entrelacs. Paris: Firmin-Didot; 1879.

6. Schneider G. Geometrische Bauornamente der Seldschuken in Kleinasien. Wiesbaden: Reichert; 1980.

7. Critchlow K. Islamic patterns: an analytical and cosmological approach. London: Thames \& Hudson; 1983.

8. Hankin EH. The drawing of geometric patterns in saracenic art. New Delhi: The Director General Archaeological Survey of India; 1998.

9. Cromwell PR. The search for quasi-periodicity in Islamic 5-fold ornament. Math Intell. 2009;31:36-56. https://doi.org/10.1007/s00283-008-9018-6.

10. Bodner BL. From Sultaniyeh to Tashkent Scrolls: euclidean constructions of two nine- and twelve-pointed interlocking star polygon designs. Nexus Netw J. 2012;14(2):307-32. https://doi.org/10.1007/ s00004-012-0111-y.

11. Agirbas A. Algorithmic decomposition of geometric Islamic patterns: a case study with star polygon design in the tombstones of Ahlat. Nexus Netw J. 2020;22:113-37. https://doi.org/10.1007/s00004-018-0416-6.

12. Redondo-Buitrago A, Huylebrouck D. Nonagons in the Hagia Sophia and the Selimiye Mosque. Nexus Netw J. 2015;17(1):157-81. https://doi.org/ 10.1007/s00004-015-0235-y.

13. Uluengin FM. Mukarnas. Istanbul: Istanbul Fetih Cemiyeti; 2018.

14. Necipoglu G. The Topkapi scroll: geometry and ornament in Islamic Architecture: Topkapi Palace Museum Library MS H. 1956. Santa Monica: The Getty Center for the History of Art and the Humanities; 1995.

15. Ozdural A. Giyaseddin Jemshid el-Kashi and stalactites. METU JFA. 1990;10:31-49.

16. Dold-Samplonius Y, Harmsen SL. The muqarnas plate found at Takht-i Sulayman: a new interpretation. Muqarnas Ann Vis Cult Islam World. 2005:22:85-94.

17. Elkhateeb AA. Domes in the Islamic architecture of Cairo City: a mathematical approach. Nexus Netw J. 2012;14(1):151-76. https://doi.org/10. 1007/978-3-0348-0393-9_12.

18. Hamekasi N, Samavati FF, Nasri A. Interactive modeling of Muqarnas. In: Proceedings of computational aesthetics in graphics, visualization, and imaging. 2011. p. 129-36.

19. Castera J-M. The Muqarnas dome of the hall of the two sisters in the Alhambra in Granada. In: Emmer M, editor. Mathematics and culture V. Berlin: Springer; 2007. p. 101-10.
20. Kharazmi M, Sarhangi R. An analytical study of the methods of design and geometric constructions in architectural ornaments of the friday mosque of Forumad. Nexus Netw J. 2016;18:275-310. https://doi.org/10. 1007/s00004-015-0278-0.

21. Gherardini F, Leali F. A framework for 3D pattern analysis and reconstruction of Persian architectural elements. Nexus Netw J. 2016;18:133-67. https://doi.org/10.1007/s00004-015-0287-z.

22. Kashef M. Bahri Mamluk muqarnas portals in Egypt: survey and analysis. Front Archit Res. 2017;6:487-503. https://doi.org/10.1016/j.foar.2017.09. 004.

23. Yaghan MAJ. The Muqarnas pre-designed erecting units: analysis, definition of the generic set of units, and a system of unit- creation as a new evolutionary step. Archit Sci Rev. 2001;44(3):297-318. https://doi.org/10. 1080/00038628.2001.9697485.

24. Takahashi S. Muqarnas: a three-dimensional decoration of Islamic Architecture. 2020. http://www.shiro1000.jp/muqarnas/default-.htm. Accessed 31 July 2020.

25. Agirbas A, Yildiz G. Origin of irregular star polygons in ground projection plans of muqarnas. Nexus Netw J. 2021;23:507-48. https://doi.org/10. 1007/s00004-020-00516-X.

26. Hasol D. Ansiklopedik Mimarlik Sozlugu. Istanbul:Yem Yayınevi; 2002.

27. Karademir M. The portal design of the mosques in Sinan's period. Selcuk Univ J Stud Turcol. 2016;40:299-314

28. Gunay R. Sinan'in Istanbul'u (Birinci Baski). Istanbul:Yem Yayınevi; 2006.

29. Eris I, Yuzeroglu U, Demir N. Atik Valide Sultan Kulliyesi 2011-2013 Yillari Restorasyonu ve Uygulamalari. Vakif Restorasyon Yilligi Dergisi. 2013;6:99-114.

30. Seker BS. Mimar Sinan Camilerinin Statik ve Dinamik Yukler Etkisinde Davranislarinin Incelenmesi. Doktora Tezi, Karadeniz Teknik Universitesi, Fen Bilimleri Enstitusu, Trabzon; 2011.

31. Stiny G. Shape: talking about seeing and doing. Cambridge: MIT Press; 2006.

32. Knight T, Stiny G. Making grammars: from computing with shapes to computing with things. Des Stud. 2015;41:8-28. https://doi.org/10.1016/j. destud.2015.08.006.

33. Odekan A. Sedat Cetintas. Restorasyon Yilligi Dergisi. 2015;11:88-93.

34. Kuban D. Osmanli Mimarisi. Istanbul: Yem Yayınevi; 2007.

35. Odekan A. Yazilari ve Roloveleriyle Sedat Cetintas. Istanbul: ITU Yayinlari; 2004.

\section{Publisher's Note}

Springer Nature remains neutral with regard to jurisdictional claims in published maps and institutional affiliations.

\section{Submit your manuscript to a SpringerOpen ${ }^{\circ}$ journal and benefit from:}

- Convenient online submission

- Rigorous peer review

- Open access: articles freely available online

- High visibility within the field

- Retaining the copyright to your article

Submit your next manuscript at springeropen.com 